\title{
Strategies toward long-life light-emitting electrochemical cells
}

\author{
Jun $\mathrm{Gao}^{1 *}$ \\ ${ }^{1}$ Department of Physics, Engineering Physics and Astronomy, Queen's University, Kingston, \\ Ontario, K7L 3N6, Canada
}

Key words: light-emitting electrochemical cells; lifetime; degradation; electrochemical doping

\begin{abstract}
This mini-review examines the operational lifetime of light-emitting electrochemical cells (LECs). Under continuous operation, both polymer-based LECs (PLECs) and ionic transition metal complex (iTMC)-based LECs (iTMC-LECs) now exhibit a luminance half-life exceeding 1,000 hours. This improved performance is accomplished with several effective strategies aimed at optimizing the operating scheme, the material composition, and the device architecture. These strategies are presented in detail with PLECs as an example. iTMC-LECs are also highlighted due to their excellent stress stability with regards to both luminance and operating voltage. The survey of literature data points to clear trends, as well as some unexpected results in LECs stressed for an extended period. Major challenges still exist, but long-lasting LECs are possible when the proven strategies are combined with innovative materials and device design.
\end{abstract}

\footnotetext{
*Email: jungao@queensu.ca
} 


\section{Introduction}

Light-emitting electrochemical cells (LECs) are solid-state electroluminescent (EL) devices whose active medium is a luminescent, mixed ionic/electronic conductor.[1-3] The intentionally added mobile ions distinguish LECs from other types of molecular devices. First developed in the $90 \mathrm{~s}$ as an alternative to the polymer light-emitting diodes (PLEDs), LECs now employ a variety of luminescent materials such as conjugated polymers (CPs),[4-11] organic small molecules (SMs),[12-14] and ionic transition metal complexes (iTMCs)[15-22]. LECs are attractive molecular devices for potential display and lighting applications due to their simple device structure, compatibility with low-cost solution processing techniques, and highly desirable device characteristics.[23,24]

Prototypical PLECs are based on a composite of a luminescent $\mathrm{CP}$ and a polymer electrolyte.[25,26] The latter is typically a complex of polyethylene oxide (PEO) and a lithium triflate salt (LiTf). The presence of mobile ions, contributed by the polymer electrolyte, causes in situ electrochemical p- and n-doping of the luminescent CP when they interact with injected holes and electrons. The doped CP exhibits vastly increased conductivity. As a result, LECs are insensitive to electrode work functions and active layer thickness. This affords LECs an efficient single layer construction, thicker active layers, and air-stable electrode materials. Light emission in a LEC takes place when the contrarily moving doping fronts make contact to form a p-n or $\mathrm{p}$ i-n junction.

The introduction of ionic charges, on the other hand, also complicates the LEC processes. The LEC doping process and junction structure continue to be an important subject of research all on their own.[27-33] Over the past twenty years, our understanding of LECs has greatly improved. LEC device performance, however, is still lagging behind that of PLEDs or OLEDs in the operational lifetime. For example, state-of-the-art, solution-processed PLEDs created by Cambridge Display Technology (CDT) exhibit a T95 lifetime (accelerated tests) of 5,800 hrs and 7,500 hrs respectively for red and green-emitting devices with an initial luminance of 1,000 $\mathrm{cd} / \mathrm{m}^{2}$. The T50 lifetimes are on the order of hundreds of thousands of hours.[34] By comparison, the longest reported LEC lifetime is about two orders of magnitude lower. This review seeks to identify effective strategies that can address this key deficiency of LECs. PLECs will be used as a primary example and examined in detail. The review points to a challenging, yet also promising future for the realization of long-life LECs. The review is organized into nine sections. 
In Section II, a literature survey of PLEC lifetime data is given. In Sections III-VI, various strategies for long-life PLECs are discussed. In Section VII, long-life iTMC-LECs are introduced. Section VIII outlines the challenges and opportunities for an improved LEC operational lifetime. Finally, Section IX provides conclusions and an overall outlook.

\section{Literature Survey of PLEC Lifetime Data}

Figure 1 captures representative PLEC operational lifetime data reported over the past 20 years. The data are limited to studies with a sufficient test duration ( $\geq 10$ hours) and/or peak luminance $\left(100 \mathrm{~cd} / \mathrm{m}^{2}\right)$. In Figure 1(a), the PLEC lifetime is plotted against the year of publication. In general, PLEC operational lifetime data are quite scarce when compared with other performance figures of merit such as peak luminance or efficiency. This is especially true in the first decade after the invention of PLECs. The reporting of such data, however, increased in volume around 2009, when an operational lifetime of $\sim 1,000$ hours was first noted. It should be cautioned here that the PLECs in these studies differ significantly in their structures, materials, and test conditions. And the operational lifetime, as a key figure of merit, was not defined in the same way in these studies. Lifetime values are directly quoted from the publications without any attempt to extrapolate, calibrate, or normalize. Some represent the time needed for luminance to drop below a certain percentage (50\%-95\%) of peak luminance, [8,3545] while some are simply the test durations, [46-49] and some are defined as the duration wherein the luminance is above a certain level $\left(100 \mathrm{~cd} / \mathrm{m}^{2}\right.$ or $\left.300 \mathrm{~cd} / \mathrm{m}^{2}\right) \cdot[6,50-54]$

Despite the lack of a standard definition, clear patterns emerge when the lifetime data are plotted against the peak luminance of tested cells, as shown in Figure 1(b). The longest lasting PLECs, concentrated in the top left, were all operated at a low peak luminance of 100-200 $\mathrm{cd} / \mathrm{m}^{2} \cdot[6,50,52]$ As expected, operational lifetime decreases with the peak luminance of the tests. On the bottom right of the graph, one study stands out for its high peak brightness up to 5,500 $\mathrm{cd} / \mathrm{m}^{2}$.[42] When operated at 2,200 cd/m², the cell exhibited a T75 lifetime of 102 hours. The extrapolated lifetime at $100 \mathrm{~cd} / \mathrm{m}^{2}$ reached a record 27,000 hours. The details of these longestlasting cells are summarized in Figure 1 (c). Also included in Figure 1 (c) is a white PLEC with a very promising T80 lifetime of about 13 hours when tested with a high peak luminance of over $1,200 \mathrm{~cd} / \mathrm{m}^{2}$. Many considerations went into the design and testing of these high-performing PLECs. In the following sections, some of the design strategies will be examined regarding their rationale, merits, as well as drawbacks. In doing so, we hope to synthesize new routes that can 
potentially lead to even longer lifetimes.

(a)

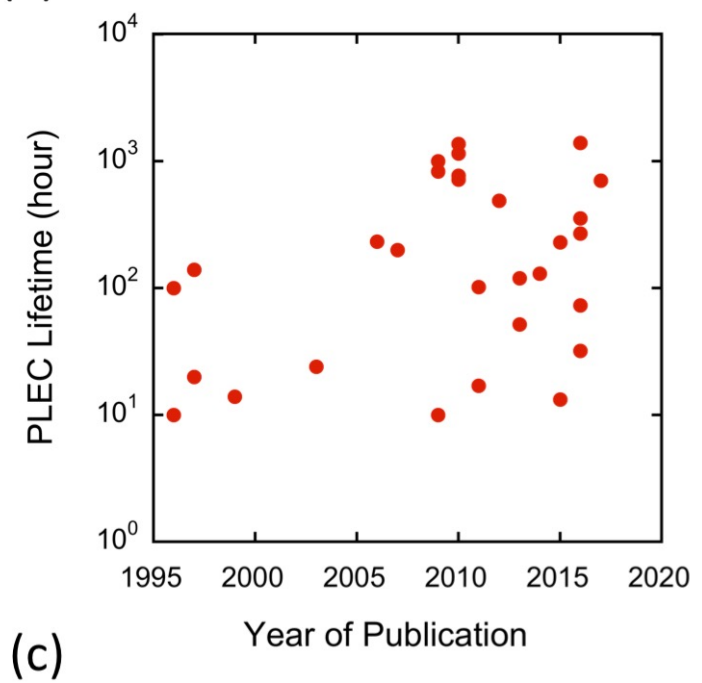

(b)

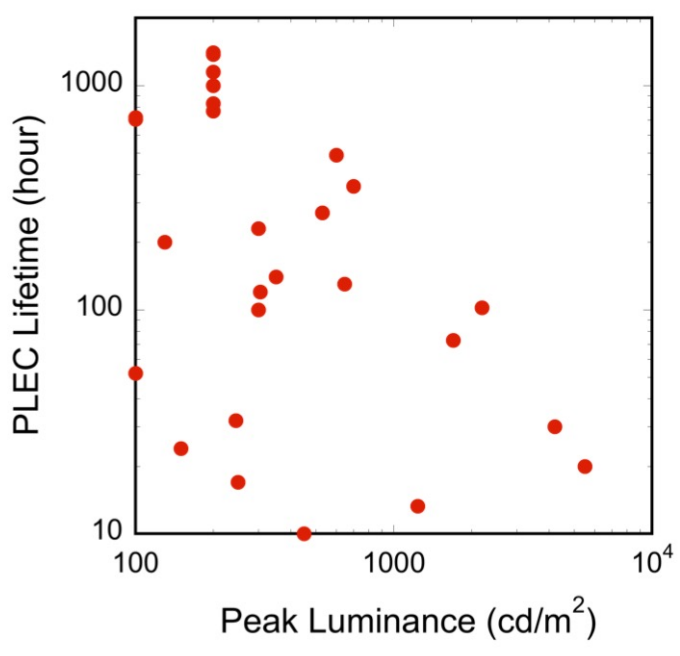

\begin{tabular}{|c|c|c|c|c|}
\hline PLEC Structure & Operating Current & $\begin{array}{l}\text { Peak } \\
\text { Luminance }\end{array}$ & $\begin{array}{l}\text { Lifetime } \\
\text { (hour) }\end{array}$ & $\begin{array}{l}\text { Peak } \\
\text { Efficiency }\end{array}$ \\
\hline $\begin{array}{l}\text { ITO/PEDOT:PSS/MEH- } \\
\text { PPV:PEO: } \mathrm{KCF}_{3} \mathrm{SO}_{3} / \mathrm{Al}\end{array}$ & $\begin{array}{l}5 \mathrm{~mA} \text { for } 0.5 \text { hour, } \\
\text { followed by } 1 \mathrm{~mA}\end{array}$ & $\sim 200 \mathrm{~cd} / \mathrm{m}^{2}$ & $\sim 1,000$ & $1.9 \mathrm{Im} / \mathrm{W}$ \\
\hline $\begin{array}{l}\text { ITO/PEDOT:PSS/SY:TMP } \\
\text { E:LiCF } \mathrm{SO}_{3} / \mathrm{Al}\end{array}$ & $\begin{array}{l}7.7 \mathrm{~mA} / \mathrm{cm}^{2} \\
\text { prebias followed by } \\
1.9 \mathrm{~mA} / \mathrm{cm}^{2}\end{array}$ & $\sim 200 \mathrm{~cd} / \mathrm{m}^{2}$ & 1,150 & $\begin{array}{l}8.6 \mathrm{~lm} / \mathrm{W} \\
8.6 \mathrm{~cd} / \mathrm{A}\end{array}$ \\
\hline $\begin{array}{l}\text { ITO/PEDOT:PSS/SY:PS:T } \\
\text { MPE:LiCF } \mathrm{SO}_{3} / \mathrm{Al}\end{array}$ & $\begin{array}{l}7.7 \mathrm{~mA} / \mathrm{cm}^{2} \\
\text { prebias followed by } \\
1.9 \mathrm{~mA} / \mathrm{cm}^{2}\end{array}$ & $\sim 200 \mathrm{~cd} / \mathrm{m}^{2}$ & 1,375 & $10.2 \mathrm{~lm} / \mathrm{W}$ \\
\hline $\begin{array}{l}\text { ITO/SY:TMPE- } \\
\text { OC:LiCF } \mathrm{SO}_{3} / \mathrm{Al}\end{array}$ & $\begin{array}{l}7.7 \mathrm{~mA} / \mathrm{cm}^{2} \text { for } 40 \\
\mathrm{~min} \text { followed by } \\
1.9 \mathrm{~mA} / \mathrm{cm}^{2}\end{array}$ & $\sim 200 \mathrm{~cd} / \mathrm{m}^{2}$ & 1,400 & $18.1 \mathrm{~lm} / \mathrm{W}$ \\
\hline $\begin{array}{l}\text { ITO/SY:PEO- } \\
\text { DMA:LiCF } \mathrm{SO}_{3} / \mathrm{Al}\end{array}$ & $25 \mathrm{~mA} / \mathrm{cm}^{2}$ & $2,200 \mathrm{~cd} / \mathrm{m}^{2}$ & 102 (T75) & $15.3 \mathrm{~lm} / \mathrm{W}$ \\
\hline $\begin{array}{l}\text { ITO/WLEP:ETPTA:LiCF } S_{3} \\
\mathrm{O}_{3} / \mathrm{Al}\end{array}$ & $13.3 \mathrm{~mA} / \mathrm{cm}^{2}$ & $1,241 \mathrm{~cd} / \mathrm{m}^{2}$ & $13.3(\mathrm{~T} 80)$ & $8.1 \mathrm{~cd} / \mathrm{A}$ \\
\hline
\end{tabular}

Figure 1. (a) Published PLEC operational lifetime vs. year of publication. (b) Published PLEC lifetime vs. peak luminance of stress test. (c) Details of some long-life PLECs from references $[6,42,50,52,55]$

\section{Optimizing electrolyte loading}

Early PLECs typically contained a large quantity of electrolyte materials. For example, a weight ratio of PPV:PEO: LiTf=50:50:8.9 was used in one of the original PLECs.[25] This corresponds to an $\mathrm{EO} / \mathrm{Li}^{+}$molar ratio of $20: 1$, which has been shown to exhibit the highest ionic 
conductivity in PEO:LiTf complexes when the salt concentration is varied.[56] The PLECs, containing more that $50 \%$ electrolyte by weight in their active layers, exhibited symmetric light intensity vs. voltage ( $\mathrm{L}$ vs. V) and antisymmetric current vs. voltage (I vs. V) characteristics that are unique to LECs. PLECs with high electrolyte loading, however, exhibited a T50 lifetime of only 6-10 hours and were slow to turn on. This has been attributed to the poor film quality of the PLEC active layer, which was comprised of two incompatible high polymers.[35]

A 2009 study explored the effect of electrolyte loading on the operational lifetime of MEH-PPV:PEO: $\mathrm{KCF}_{3} \mathrm{SO}_{3}$ LECs.[50] Starting from an active layer composition of $\mathrm{MEH}$ PPV:PEO: $\mathrm{KCF}_{3} \mathrm{SO}_{3}=1: 1.35: 0.25$, which corresponded to a $\mathrm{EO} / \mathrm{K}^{+}$molar ratio of $23: 1$, the salt content was progressively reduced to 1:1.35:0.03. Reducing the salt concentration was found to incur a minimal loss of power efficiency or a loss of operational lifetime. Next, the PEO content was reduced with the MEH-PPV and salt contents fixed at 1:0.03. This, however, resulted in a 30-fold increase in the operational lifetime when the PEO content was lowered from 1:1.35 to 1:0.085, as shown in Figure 2 (a). A record lifetime of nearly 1,000 hrs had been achieved with an optimized electrolyte amount. This is shown in Figure 2 (b).

Because PLEDs based on an orange-emitting polymer similar to MEH-PPV exhibited a lifetime of over 10,000 hours,[57] it is highly probable that the poor lifetime of PLECs is caused by adverse reactions involving the electrolyte. Reducing the electrolyte loading, so long the doping process is not impeded, should benefit the stability of PLECs. The results of Figure 2 demonstrate the effectiveness of such an approach. In fact, all PLECs listed in Figure 1 (c) had a low electrolyte content of about $10 \%-20 \%$ by weight. These PLECs also exhibited high efficiencies and characteristic LEC turn-on/activation behaviors. A tradeoff of this approach is a slow turn-on response under a fixed voltage bias, as shown in Figure 2 (a). This drawback can be overcome by activating the PLEC with a variable current driving scheme, as shown in Figure 2 (b). Reducing the amount of electrolytes, however, does not solve the PLEC longevity problem in its entirety and is unsuited for application in extremely large planar PLECs. PLECs with reduced electrolyte loading also lose the symmetric/antisymmetric L-V/I-V characteristics. [58] The unique device behaviors of PLECs under reverse bias operation will be discussed in Section IV and Section VIII. 


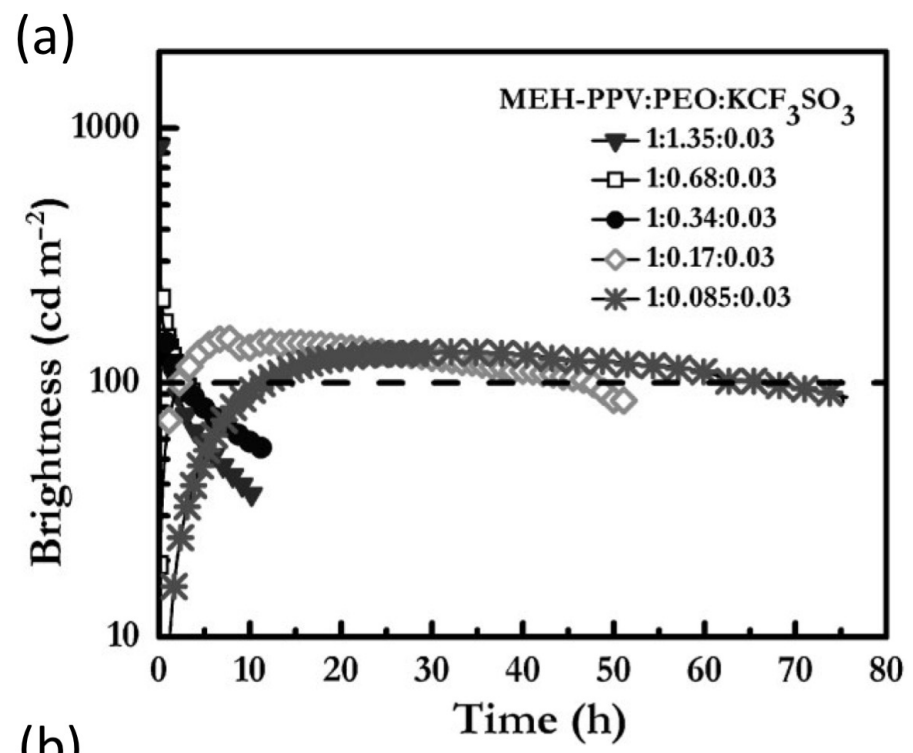

(b)

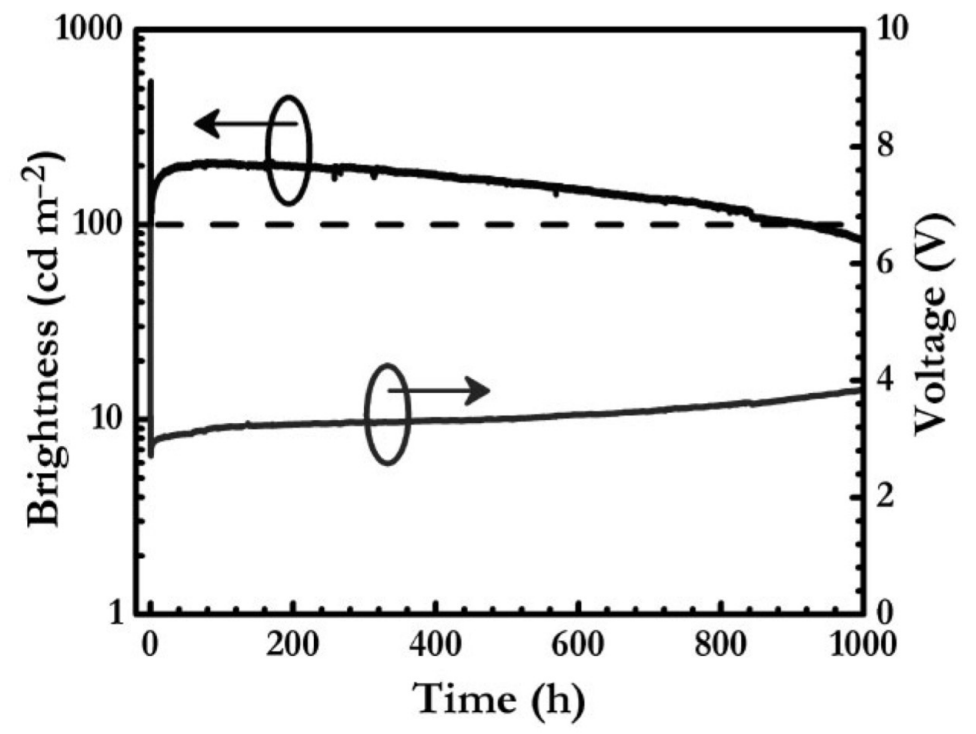

Figure 2. (a) The temporal evolution of the brightness of ITO/MEH-PPV:PEO: $\mathrm{KCF}_{3} \mathrm{SO}_{3} / \mathrm{Al}$ sandwich cells with different PEO concentration in the active material, as specified in the upper inset. The devices were tested at $\mathrm{V}=3 \mathrm{~V}$ and $\mathrm{T}=360 \mathrm{~K}$. (b) The temporal evolution of the brightness (upper line) and the voltage (lower line) of an ITO/PEDOT-PSS/MEH PPV:PEO: $\mathrm{KCF}_{3} \mathrm{SO}_{3} / \mathrm{Al}$ sandwich cell with an active material mass ratio of 1:0.085:0.03. The device was operated at $\mathrm{T}=298 \mathrm{~K}$ and in galvanostatic mode. The initial "pre-bias"' current, Ipre-bias $=0.005 \mathrm{~A}$, was applied for $\mathrm{t}=0.5 \mathrm{~h}$, and it was followed by long-term operation at I=0.001 A. Reprinted (adapted) with permission from (Fang, J., Matyba, P., and Edman, L., The Design and Realization of Flexible, Long-Lived Light-Emitting Electrochemical Cells. Advanced Functional Materials, 2009, 19, 2671-2676). Copyright (2009) WILEY-VCH.

\section{Freezing or chemically fixing the PLEC junction}


To completely overcome the main drawbacks of PLECs, namely fast degradation and a slow turn-on response, it is desirable that a PLEC, once activated, de-couples itself from any ionic processes. In other words, a PLEC with a fixed junction, much like an inorganic $p-n$ or $p-i-$ $\mathrm{n}$ junction LED, is needed. The route to a fixed PLEC junction lays with the polymer electrolyte, which has been the subject of intense research effort due to its applications in rechargeable batteries, fuel cells, and recently, dye-sensitized solar cells.[59,60] Ion transport in a polymer electrolyte has been known to be highly dependent on temperature. In PEO/ $\mathrm{Li}^{+}$complexes, for example, cation transport is enabled by polymer chain segmental motion, which forms and breaks coordination bonds between the $\mathrm{Li}^{+}$ion and the ether oxygen. The chain motion also creates "free volume" that provides space for ions to move into. The amorphous phase of the $\mathrm{PEO} / \mathrm{Li}^{+}$complex is mainly responsible for the ion conductivity, whose temperature dependence can be described by an exponential relation known as the Vogel-Tamman-Fulcher (VFT) equation.[61] Since polymer chain segmental motion ceases below the glass transition temperature $\left(\mathrm{T}_{\mathrm{g}}\right)$, a freeze-out of ion motion and conduction also occurs. This important polymer electrolyte property was exploited to create a "frozen-junction" LEC in 1997.[62] A ITO/MEHPPV:PEO:LiTf/Al PLEC was activated at room temperature and subsequently cooled to $100 \mathrm{~K}$, which was well below the $\mathrm{T}_{\mathrm{g}}$ of PEO:LiTf complex at about $208 \mathrm{~K}$.

Frozen-junction PLECs exhibit sub-microsecond response times and diode-like I-V and L$\mathrm{V}$ characteristics. Significant current flow and EL only occur when the bias polarity is the same as that of the activation voltage bias. More importantly, frozen-junction PLECs exhibit enhanced stability and minimal efficiency roll-off even when driven to a current density of $300 \mathrm{~mA} / \mathrm{cm}^{2}$. When driven with a constant current density of $5 \mathrm{~mA} / \mathrm{cm}^{2}$ at $200 \mathrm{~K}$, EL intensity decreased only by $5 \%$ from the initial value after more than 10 hours of continuous operation.[38]

Fluorescence imaging of extremely large planar PLECs offer direct evidence of a static doping profile at temperatures below $\mathrm{T}_{\mathrm{g}}$.[63] A stress test of such frozen planar PLECs initially yielded puzzling behaviors--both driving voltage and EL intensity increased rapidly over an extended period of more than 150 hours.[64] This was later attributed to the effect of self-heating by the device being tested.[65] The heating caused partial relaxation of the frozen junction, which in turn made the device more resistive but less quenched, hence the observed increase in both EL intensity and driving voltage. The relationship between doping-induced quenching and EL intensity/decay will be discussed in more detail in Section V. By fabricating the planar 
PLECs on a sapphire substrate instead of a glass substrate, the real cell temperature was close to that of the cold finger due to sapphire's excellent thermal conductivity. This resulted in a "normal" stress response in EL intensity and driving voltage, as shown in Figure 3.

(a)

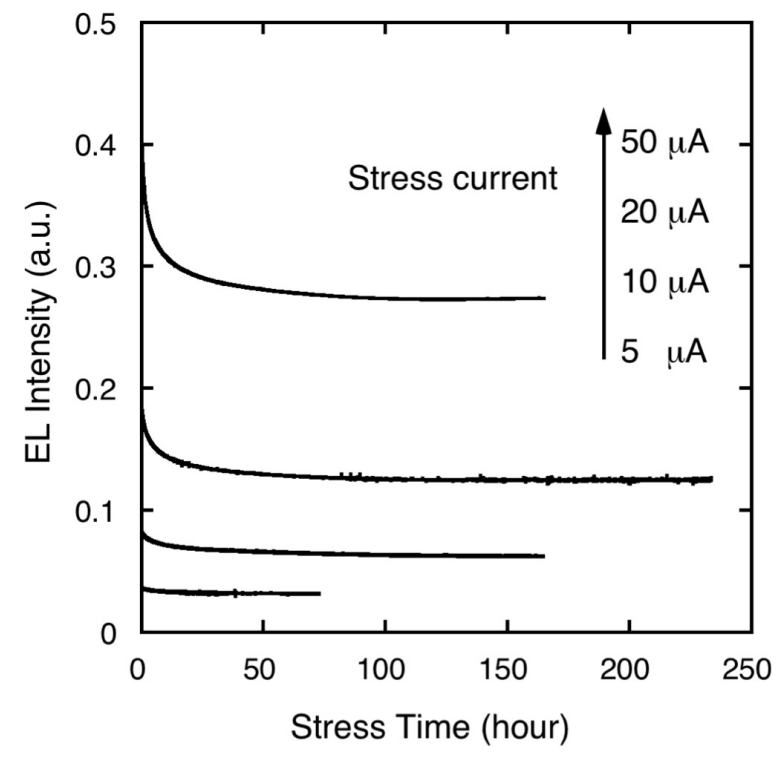

(b)

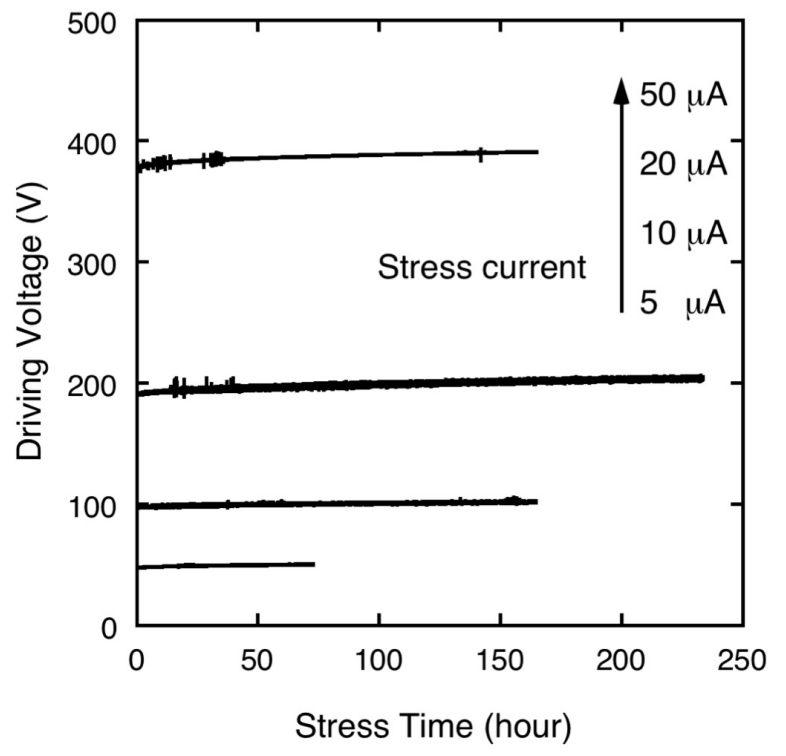

Figure 3. (a) Time evolution of EL intensity for identical $0.6 \mathrm{~mm}$ frozen-junction planar PLECs operated under various currents at $200 \mathrm{~K}$. (b) Time evolution of device driving voltage for cells operated in (a). Reprinted (adapted) with permission from (Zhang, Y. and Gao, J., Lifetime study of polymer lightemitting electrochemical cells. Journal of Applied Physics 2006, 100, 084501). Copyright (2006) American Institute of Physics.

The stress behaviors of these frozen-junction PLECs are very different from those of dynamic-junction PLECs operated at room temperature (RT). The EL intensity initially 
experienced a sharp decline. Afterwards, both EL and driving voltage barely changed. The EL intensity, in particular, was nearly flat. A most remarkable fact about these stress tests is the extremely high current density used, up to $1,000 \mathrm{~mA} / \mathrm{cm}^{2}$ for a $50 \mu \mathrm{A}$ stress current. During the 165 -hour stress at $50 \mu \mathrm{A}, 594,000 \mathrm{C} / \mathrm{cm}^{2}$ of charge had passed through the polymer film/junction. This corresponds to a very high degree of redox stability that is comparable to a PLED with a half-life of 20,000 hours stressed at $8.3 \mathrm{~mA} / \mathrm{cm}^{2}$.[57]

For practical applications, frozen-junction PLECs need to operate at RT. Two general approaches have been explored to realize an RT frozen-junction PLEC. The first exploits electrolyte materials with a melting or glass transition above RT. The PLECs are first activated via heating or self-heating to establish doping and a light-emitting junction. The PLECs are subsequently cooled to RT to freeze the junction. RT frozen-junction PLECs have been demonstrated with crown ether-based electrolytes,[66,67] a light-emitting polyelectrolyte[68], a high $T_{\mathrm{g}}$ random copolymer-lithium complex, [69] and an ionic liquid.[40] The second approach involves chemically fixing the PLEC junction after its formation via the use of cross-linkable or polymerizable materials.[70] One method uses polymerizable ion pairs or ionic liquids to fix the junction during the charging process.[71-74] Ion-transport materials such as a liquid ion conductor containing cross-linkable methacrylate groups can also be cross-linked to immobilize the dopant ions.[41,55,70] The various chemical stabilization techniques were compared, and the best overall results were obtained when both the counterions and the ion-transport materials were polymerized using a radical-initiator compound.[75] With a photo-sensitive initiator compound, junction stabilization can also be realized "on demand" with UV exposure.[76] Finally, a stabilized p-n heterojunction has been demonstrated using a two-layer structure that consists of a conjugated cationic polyelectrolyte and a neutral, anion-trapping conjugated polymer underlayer.[77]

The various RT frozen-junction PLECs show promising device performance and junction stability. Some devices exhibit brightness and efficiency comparable to those of dynamicjunction PLECs.[41,66] Using PEO capped with methacrylate end groups and the LiTf salt as an electrolyte, highly efficient PLECs were demonstrated to last for more than 100 hours at a peak luminance of $2,200 \mathrm{~cd} / \mathrm{m}^{2}$. This excellent stress lifetime was attributed to a stabilized junction when the methacrylate groups are polymerized during operation.[42] The RT frozen junctions, 
when left under an open-circuit condition, are stable for a test duration ranging from an hour $[67,68]$, tens of hours $[41,69,75,76]$, to two weeks.[77]

While RT frozen junctions can be realized with novel electrolyte materials, an unexpected solution also exists. Consider again the prototypical ITO/MEH-PPV:PEO:LiTf/Al cell that was cooled to create the first frozen-junction PLEC. If PEO is entirely removed from the active layer, the resulting cell is not expected to function properly. MEH-PPV, which is non-polar and has a $\mathrm{T}_{\mathrm{g}}$ above RT [78,79], is not a solvent of LiTf salt. Surprisingly, the ITO/MEH-PPV:LiTf/Al cells can be activated with a large voltage bias to emit under either a forward or a reverse bias. The activated cells displayed strong evidence of doping and photovoltaic response that was consistent with the formation of a doping-induced junction.[80,81] More importantly, the activated state was stable at RT. As shown in Figure 4 (a), the photovoltaic polarity was reversed after the cell was activated with a reverse bias. The signs of both open-circuit voltage $\left(\mathrm{V}_{\mathrm{OC}}\right)$ and a short-circuit current $\left(\mathrm{I}_{\mathrm{SC}}\right)$ were consistent with the polarity of the PLEC junction formed. The resulting positive $\mathrm{I}_{\mathrm{SC}}$ and negative $\mathrm{V}_{\mathrm{OC}}$ did not degrade appreciatively after a total storage time of about 550 hours (Figure 4 (b)). In a green-emitting cell activated with a $-21 \mathrm{~V}$ bias and tested subsequently with fast voltage scans between 0 and $-16 \mathrm{~V}$, the luminance measured at $-16 \mathrm{~V}$ remained unchanged for 1,140 hours after an initial drop from $39 \mathrm{~cd} / \mathrm{m}^{2}$ to $32 \mathrm{~cd} / \mathrm{m}^{2}$. These results represent the RT frozen junction with the longest shelf life. 
(a)

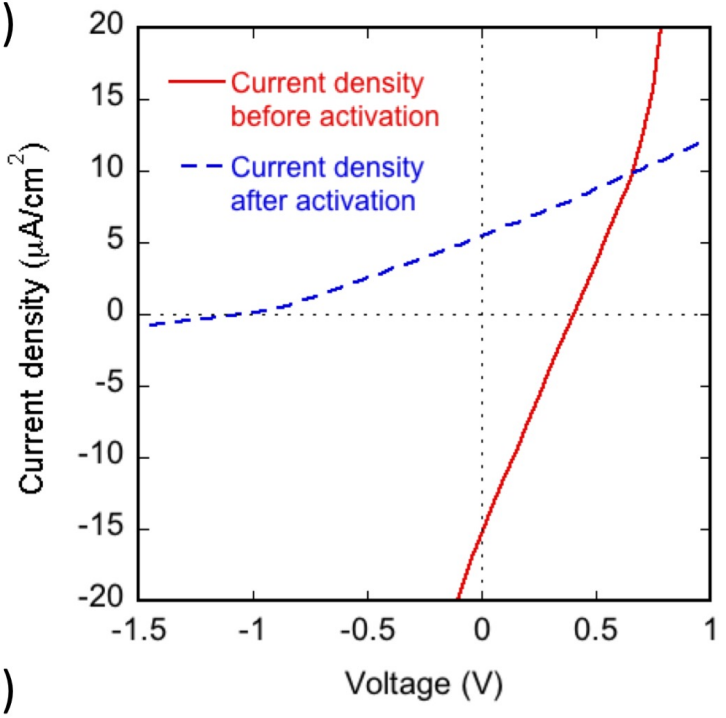

(b)

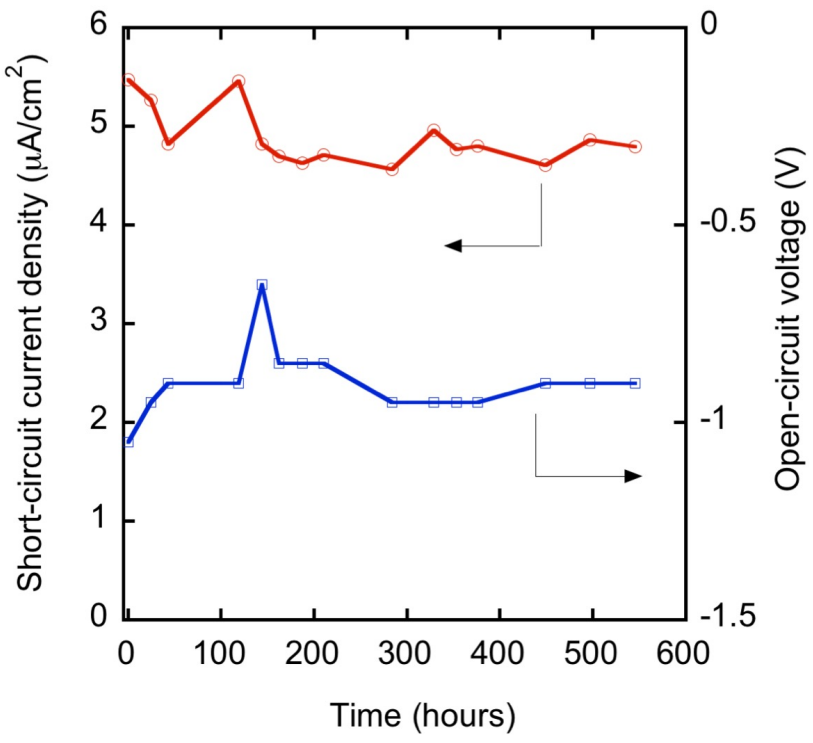

Figure 4. (a) Photovoltaic response (photocurrent vs. voltage) of a ITO/MEH-PPV:LiTf (10:1)/Al device, before and after activation under $-20 \mathrm{~V}$. (b) The shelf stability of $\mathrm{V}_{\mathrm{OC}}$ and $\mathrm{I}_{\mathrm{SC}}$ of an activated ITO/MEHPPV:LiTf (10:1)/Al device. The device was tested under AM1.5 illumination of $100 \mathrm{~mW} / \mathrm{cm}^{2}$. For shelf stability tests, the device was stored at room temperature under open-circuit conditions. Reprinted (adapted) with permission from (Gautier, B., Wu, X., AlTal, F., Chen, S. and Gao, J., Reverse bias activation of salt-doped polymer light-emitting devices. Organic Electronics 2016, 28, 47-52). Copyright (2016) Elsevier.

\section{Pulsed and Intermittent Driving}

The operational lifetime of PLECs can be measured with either a constant voltage stress or a constant current stress. A constant current stress is now a more commonly used method, the benefits of which are to facilitate a faster turn on and to compensate for the loss of luminance 
due to any increase in cell resistance. Not surprisingly, the longest-lasting PLECs shown in Figure 1(c) were all tested with a constant current stress. Figure 5 shows generic characteristic curves of a constant current stress test. The PLEC tested was an ITO/MEH-PPV:PEO:LiTf/Al sandwich cell.[45] This continuous test yielded a luminance half-life of about 230 hours at an applied constant current density of $167 \mathrm{~mA} / \mathrm{cm}^{2}$. Plotting the time axis in log scale reveals three distinct stages of the degradation process. In stage I, doping led to an increasingly balanced charge injection and an increase in luminance. The increase in luminance was accompanied by a rapid decrease in driving voltage. In stage II, the level of doping continued to increase, as evidenced by the decrease, albeit slower, of the driving voltage. The luminance, however, began its initial decline. In stage III, the decrease of luminance was accompanied by an increase in driving voltage. The first two stages are unique to LECs, while the stage III behavior is also observed in the long-term decay characteristics of a PLED.

(a)

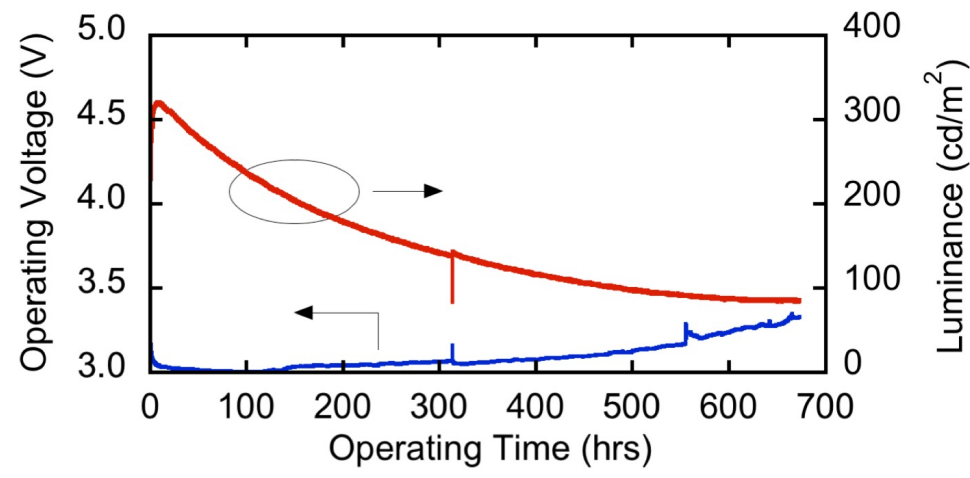

(b)

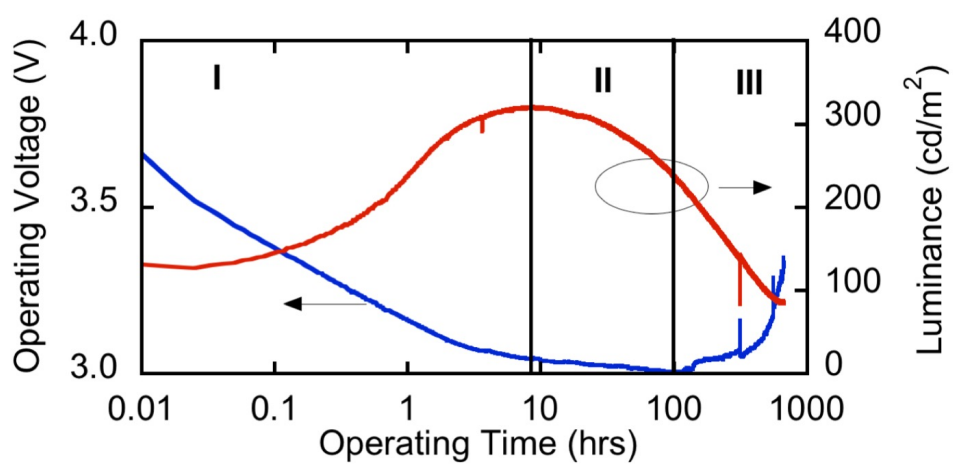

Figure 5. (a) Time evolution of luminance and operating voltage of a ITO/MEH PPV:PEO:LiTf/Al sandwich LEC (Cell 1) operated at a constant current density of $167 \mathrm{~mA} / \mathrm{cm} 2$. The cell was operated for the first time after the deposition of the top aluminum electrode. The test commenced after the deposition of the top aluminum electrode without delay. (b) The same data presented in (a) but plotted in a semi-log form with various regions of operation marked.Reprinted (adapted) with permission from (AlTal, F. and Gao, J., Long-term testing of polymer light-emitting electrochemical cells: Reversible doping and black spots. Organic Electronics 2015, 18, 1-7). Copyright (2015) Elsevier. 
Stage II, which lasted about 100 hours in this device and accounted for a near 20\% drop in luminance from the peak value, deserves special attention. Since in situ electrochemical doping is known to quench the photoluminescence (PL) of PLEC films even in a sandwich cell, $[82,83]$ is it possible that the apparent luminance decay was caused by the doping process itself? If this is the case, the loss in luminance could be reversible if the PLEC film is allowed to dedope. An intermittent testing scheme provided a definitive answer to the above question. Figure 6 shows a PLEC, similar to the one shown in Figure 5, that has been tested five times, each test lasting between 66 hours and 71 hours in each of the tests.[43] After each test (run), the cell was stored under open-circuit conduction for a month. This long storage time led to significant dedoping and the complete recovery of lost luminance in runs 2-4. In each of the five runs, the luminance decay rate increased due to the appearance of black spots and/or residue doping. The remarkable recovery of lost luminance, by simple storage, suggests that the PLEC luminance decay is not entirely irreversible!

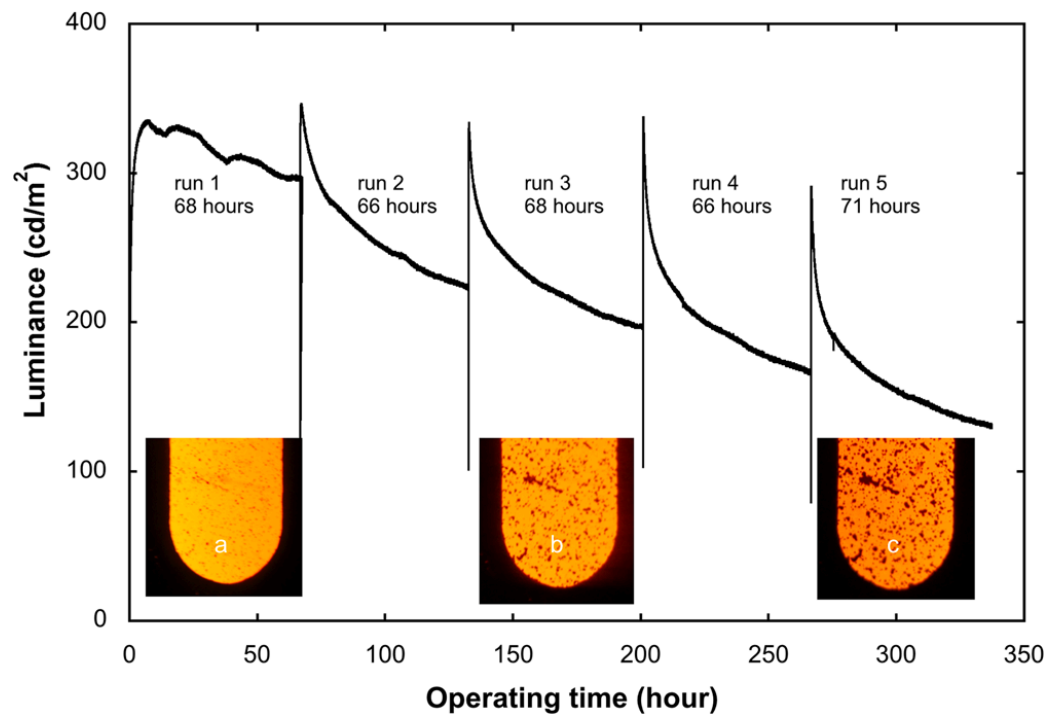

Figure 6. Time evolution of luminance and driving voltage of a ITO/MEHPPV:PEO:LiTf/Al sandwich LEC operated at a constant current of $167 \mathrm{~mA} / \mathrm{cm}^{2}$. The cell was stressed five times. The operating time indicates accumulated run time under a bias. For each run, the cell was stressed for 66-71 h. The cell was stored for a month ( $30 \pm 2$ days) in the glove box at $25{ }^{\circ} \mathrm{C}$ after each run. The first run (virgin run) commenced after the deposition of the top aluminum electrode without delay. Photographs $\mathrm{a}, \mathrm{b}$, and $\mathrm{c}$ are electroluminescent images taken at the end of runs 1,3, and 5, respectively. Identical camera settings were applied. The images show the bottom half of the cell. They have not been manipulated except for cropping. Reprinted (adapted) with permission from (Li, X., AlTal, F., Liu, G., and Gao, J., Long-term, intermittent testing of sandwich polymer light-emitting electrochemical cells. Applied Physics Letters 2013, 103, 243303). Copyright (2013) American Institute of Physics. 
The intermittent testing scheme shown above resembles a pulsed driving scheme with extremely long on and off durations. A conventional pulsed driving scheme can also be applied to PLECs, where fast pulses are used to decouple the slow ionic/doping processes from the fast electronic processes. For example, a long, initial pulse can be used to activate the PLEC, and a train of short pulses can be used for the injection of electronic charges.[84] Recently, pulsed driving was applied to a $10 \mu \mathrm{m}$-gap planar LEC made with a green-emitting co-polymer mixed with an ionic liquid.[85] As shown in Figure 7, the $1 \mathrm{~ms}$ pulses had a DC offset of $3 \mathrm{~V}$ to activate and maintain the PLEC junction. The planar PLEC reached an extraordinarily high current density of $1,036 \mathrm{~A} / \mathrm{cm}^{2}$ at $30 \mathrm{~V}$. By cooling the device down to $-20{ }^{\circ} \mathrm{C}$ to freeze the junction, the PLEC showed reduced efficiency roll-off compared to RT operation. With an even narrower pulse width of $200 \mathrm{~ns}$, the authors demonstrated a linear dependence between EL intensity and a record current density of $2 \mathrm{kA} / \mathrm{cm}^{2}$.

(a)

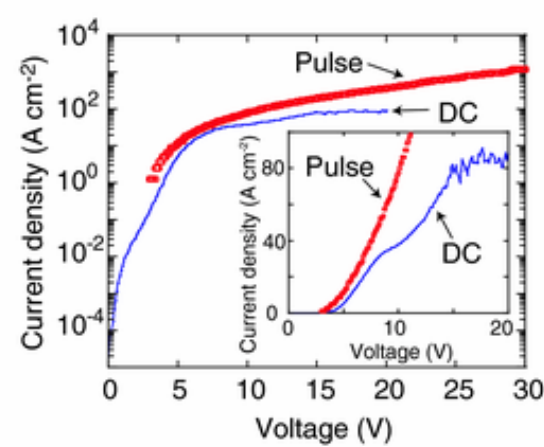

(c)

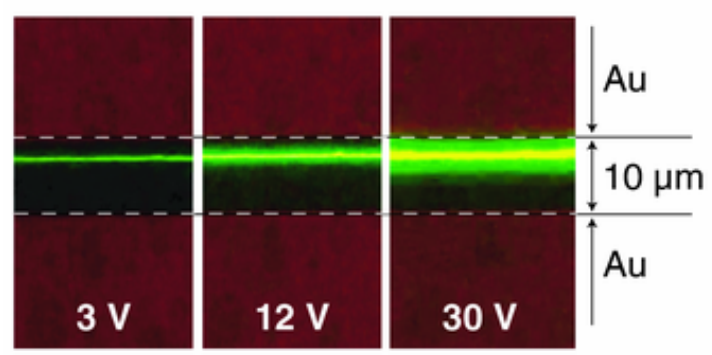

(b)

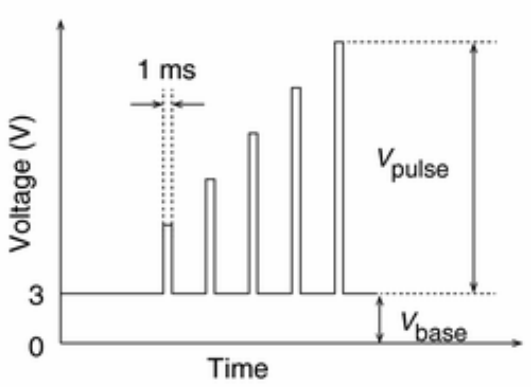

(d)

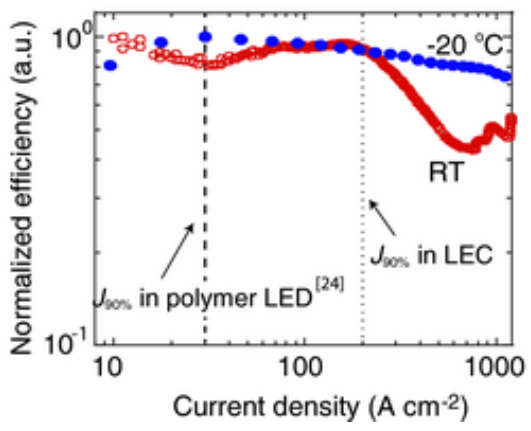

Figure 7. a) Current density-voltage characteristics of a planar LEC driven by a 1 ms voltage pulse with 3 $\mathrm{V}$ of base voltage. Standard DC measurements are also shown for comparison. Inset shows the same data replotted on a linear scale. b) Pulse-driving scheme for LEC. A constant base voltage, $V_{\text {base, }}$ of $3 \mathrm{~V}$ was applied to induce ion arrangement for $\mathrm{p}-\mathrm{n}$ homojunction formation, and a $1 \mathrm{~ms}$ pulse voltage, $V_{\text {pulse, }}$ was applied to inject electrons/holes for light emission. c) Optical microscopy of emitting LECs at $V_{\text {base }}=3 \mathrm{~V}$ and $V_{\text {pulse }}=12$ and $30 \mathrm{~V}$.d) Normalized efficiency as a function of current density at room temperature 
and at $-20{ }^{\circ} \mathrm{C}$, where the temperature is low enough to freeze ionic motion. The dashed line and dotted line represent $J 90 \%$ for polymer OLEDs in literature and for the LEC, respectively. Reprinted (adapted) with permission from (Sakanoue, T., Li, J., Tanaka, H., Ito, R., Ono, S., Kuroda, S., and Takenobu, T., High Current Injection into Dynamic p-n Homojunction in Polymer Light-Emitting Electrochemical Cells. Advanced Materials, 2017, 29, 1606392). Copyright (2017) WILEY-VCH.

These remarkable results exemplify the importance of a driving scheme to the operational stability of PLECs. Intermittent testing reveals that the apparent luminance decay in a PLEC is partially reversible. The combination of pulsed driving and frozen-junction operation allows for a PLEC to be driven to record current densities with minimal efficiency roll-off.

\section{Electrochemically stable emitters and electrolyte materials}

Although PLEDs and PLECs often use the same luminescent CPs, the PLEC operation places additional requirements on the emitters. In PLECs, CPs must possess the requisite ability to be p-and n-doped. An early study of ten soluble PPV derivatives showed that the doping potentials, as well as the reversibility of doping were dependent on the substituent groups.[86] Another study showed that the reversibility of MEH-PPV doping depended on the electrode metals used, the salt type/concentration and film thickness.[87] These results, obtained via cyclic voltammetry measurements in a liquid electrochemical cell, are mostly consistent with the observations in PLECs.[88-92] A majority of the long-life PLECs are based on Superyellow, which can be both p- and n-doped.[51] In general, a yellow/green emitter requires a lower driving current to reach the same luminance (a photometric quantity), in comparison to a red emitter such as MEH-PPV. This means that it will be more challenging to realize long-lasting blue, red and white PLECs, although many promising materials and devices have been reported.

Unlike PLEDs, PLECs also contain an electrolyte material that is as important as the emitting material. The general requirements for PLEC electrolyte materials are: (1) the ability to contribute a sufficient amount of mobile ions required for the redox doping reaction; and (2) a wide electrochemical stability window (ESW) so as not to compete with/interfere with the doping of the CP. A study of PLECs involving six PPV-based CPs and a PEO: $\mathrm{KCF}_{3} \mathrm{SO}_{3}$ electrolyte showed that the irreversible oxidation of the electrolyte was likely responsible for the poor p-doping performance of LEPs with a high oxidation potential.[93] Moreover, cathodic side reactions involving the same electrolyte could occur in a MEH-PPV-based planar PLEC.[94] A trimethylolpropane (TMPE)- $\mathrm{LiCF}_{3} \mathrm{SO}_{3}$ electrolyte, with its superior cathodic stability, was responsible for a record operational lifetime of 1,375 hours.[52] The TMPE electrolyte was 
further improved by optimizing the end group, which resulted in PLECs with a better overall performance.[6,95] Figure 8 shows the excellent performance of a PLEC made with alkyl carbonate-capped TMPE electrolytes.
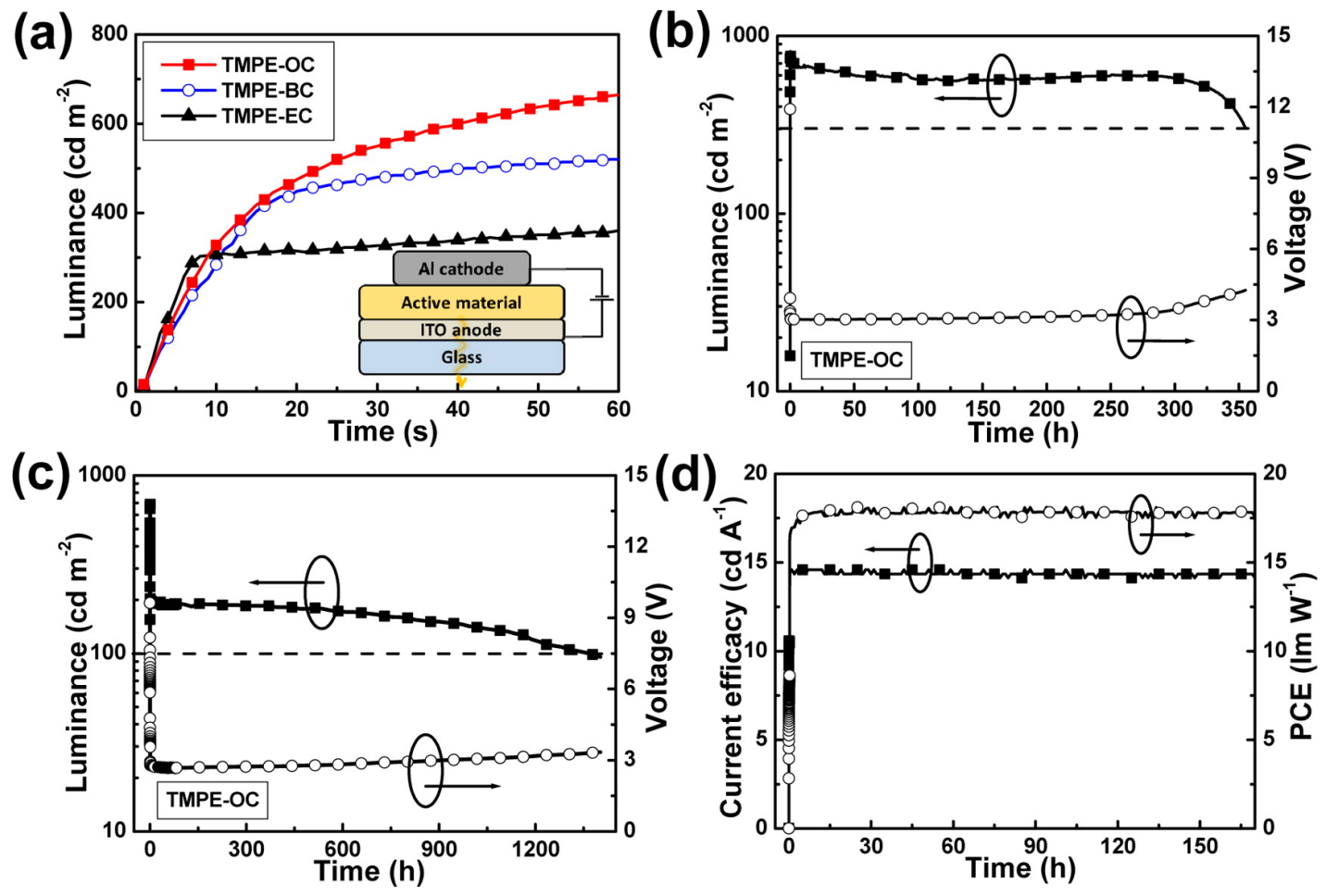

Figure 8. (a) Turn-on kinetics during the first minute of operation and (b) the long-term stability of ITO/SY + ion-transporter $+\mathrm{LiCF}_{3} \mathrm{SO}_{3} / \mathrm{Al}$ sandwich-cell LECs, with the device structure disclosed in the inset of (a). The devices were driven by $\mathrm{j}=7.7 \mathrm{~mA} \mathrm{~cm}-2$. (c) The long-term stability of a TMPE-OC device driven by a prebias of $7.7 \mathrm{~mA} \mathrm{~cm}-2$ for $40 \mathrm{~min}$ and thereafter by $1.9 \mathrm{~mA} \mathrm{~cm}-2$. (d) The temporal evolution of the efficiency for a TMPE-OC device equipped with a light-outcoupling film. The device was driven by a prebias of $7.7 \mathrm{~mA} \mathrm{~cm}-2$ for $40 \mathrm{~min}$ and thereafter by $0.77 \mathrm{~mA} \mathrm{~cm}-2$. Reprinted with permission from (Mindemark, M.;Tang, S.;Wang, J.; Kalhovirta, N.; Brandell, D. and Edman, L., HighPerformance Light-Emitting Electrochemical Cells by Electrolyte Design. Chemistry of Materials 2016, 28 (8), 2618-2623). Copyright (2016) American Chemical Society.

The miscibility of CPs and electrolyte materials is also important. In PLECs such as ITO/MEH-PPV:PEO:LiTf/Al, significant phase separation can occur between the non-polar CP and the polar PEO electrolyte. This creates a large physical separation between the $\mathrm{CP}$ to be doped and the counterions necessary for doping, and a consequently poor turn-on response and emission uniformity. Thermal annealing, followed by fast cooling, has been shown to effectively alleviate the problem.[96] By adding octylcyanoacetate, a surfactant-like additive to the PLEC blend, a fine, bi-continuous network morphology was realized. The resulting PLECs exhibit fast (ms) responses as well as a much-improved operational lifetime.[35] The latter work stimulated 
great effort to create LECs with optimized phase morphology and the demonstration of PLECs made with crown ether (CE)-based electrolytes.[37] Being a small molecule and soluble in a non-polar solvent, CE-based electrolytes brought better compatibility with CPs and fast, efficient PLECs with a good stress lifetime. Ionic liquids (ILs), or RT molten salts, can provide the necessary counterions when added to a luminescent polymer.[97-100] The device performance of IL-based PLECs strongly depends on the type of ILs and their concentration. At high concentrations, however, the composite films again suffer from phase separation, fast degradation, and compromised mechanical integrity. An alternative is to use a polymeric ionic liquid (PIL). PLECs made with a PIL show excellent device performance with PIL loading up to $50 \mathrm{wt} \%$. [101] As introduced in Section III, some ILs can also be used to realize RT frozenjunction PLECs owning to their high melting point or their ability to be polymerized.

To further improve the phase morphology of PLEC active layers, a class of bi-functional polymers has been developed. Oligo(ethylene oxide) or crown ether groups are grafted as side groups to PPVs,[102-106] polythiophenes,[107] or fluorene copolymers[108,109]. Block copolymers containing both oligo(ethylene oxide) or crown ether segments and conjugated segments were created as an alternative.[110-113] Due to the presence of ion solvating/transport moieties, these new polymers can transport both electronic and ionic charges. PLECs made with a bifunctional polymer and an added salt display characteristic LEC behaviors, such as low EL turn-on voltage and bipolar EL. Some exhibit a smoother and finer surface morphology, due to the elimination of ion-conducting polymers such as PEO.[103,106] Finally, luminescent conjugated polyelectrolytes (LCPE) [68,114-119] are multi-functional materials that are luminescent, electronically conductive, as well as being solid electrolytes. LCPEs have the advantage of being soluble in more environmentally benign polar solvents, such as water and alcohol, and allowing the fabrication of "single-component" PLECs. In general however, the device performance of these single- or two-component (polymer + salt) PLECs is inferior to conventional "three-component" PLECs. An exception is a fluorene polymer (BDOH-PF) with an ether side group.[36] When doped with LiTf salt, the resulting PLEC is highly efficient. Interestingly, adding PEO to the blend resulted in severe phase separations but a white light PLEC. Adding an iridium phosphorescent dye and lithium triflate to BDOH-PF resulted in a phosphorescent LEC which was much more efficient than PLEDs made with the same phosphorescent dye.[120] 


\section{LECs with a non-polymer emitter}

While the preceding discussions concern only PLECs, or LECs with a polymeric emitter, LECs have also been demonstrated with emitters as diverse as organic small molecules(SMs),[121-128] quantum dots,[129-131] polymer/small molecule composites, and even perovskites.[125,132] LECs based on ionic transition metal complexes (iTMCs), in particular, stand out due to their excellent device performance. iTMCs have been the topic of numerous recent reviews.[2,133-136] iTMCs, such as ruthenium or iridium-based complexes, are multi-functional compounds satisfying all the basic requirements of an LEC material. iTMCs are efficient phosphorescent emitters, semiconductors, as well as ion conductors. They also exhibit reversible redox properties and are solution-processible. Early reports of single-component, single-layer iTMC LECs show exceptional external quantum efficiency up to $5.5 \%$ and luminous

efficiency more than $10 \mathrm{~lm} / \mathrm{W}$ at low operating voltages.[137,138]Much higher efficiencies have been realized in iridium iTMC-based LECs.[139] iTMC-based LECs exhibit the same characteristic LEC transient behavior as that of PLECs.[140] The fluorescence imaging of functional planar cells confirms that iTMC-LECs,[141] along with SM-LECs [122] operate on the same basic principle as a PLEC-the electrochemical formation of a light-emitting p-n junction.

iTMCs, however, are single-ion conductors with low ionic conductivities depending on the type of counter ions, despite being single-phase systems.[137] A reflection of this fact is the absence of large, millimeter-sized planar iTMC-LECs. Planar PLECs, on the other hand, can have an interelectrode spacing of more than $10 \mathrm{~mm}$ or be activated with a $5 \mathrm{~V}$ bias voltage.[142,143] In sandwich iTMC-LECs, low ion conductivity leads to slow turn-on responses and asymmetric luminance/current vs. voltage characteristics. $[138,144]$ The response time of iTMC-LECs can be improved with the addition of ionic species, $[18,145]$ the use of an optimal driving scheme, the use of a low work function cathode,[138] or separate electron/hole injection layers.[146,147] The latter two approaches however, partially negate the processing and structural advantages of LECs. And in general, there is a tradeoff between the turn-on time, when improved with added ionic species, and the operating lifetime of iTMCs, although significant exceptions do exist. [145,148] In device characteristics, iTMC-based LECs bear some similarities to PLECs with a low electrolyte loading. They likewise exhibit excellent operational stability, as shown in the example below.[149] 
(a)

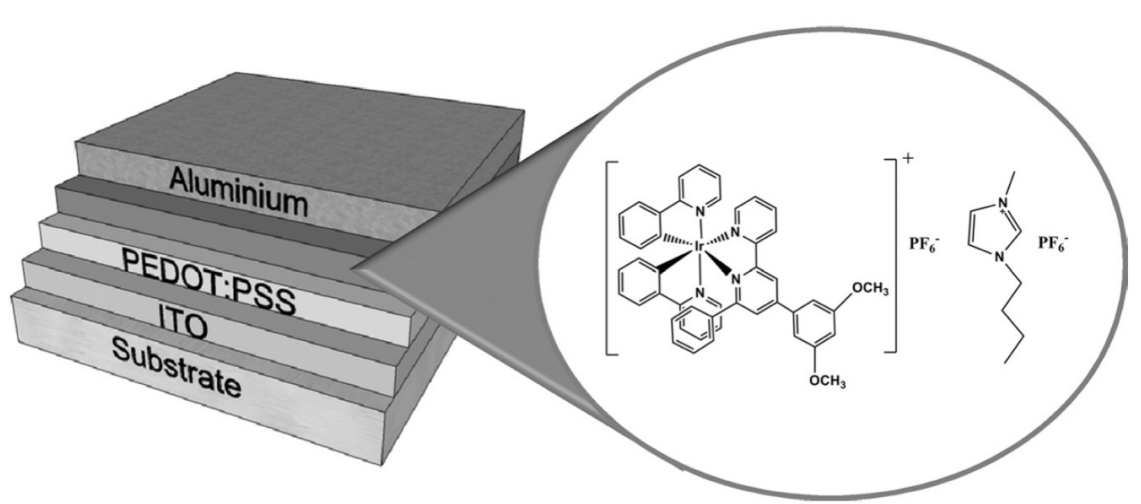

(b)

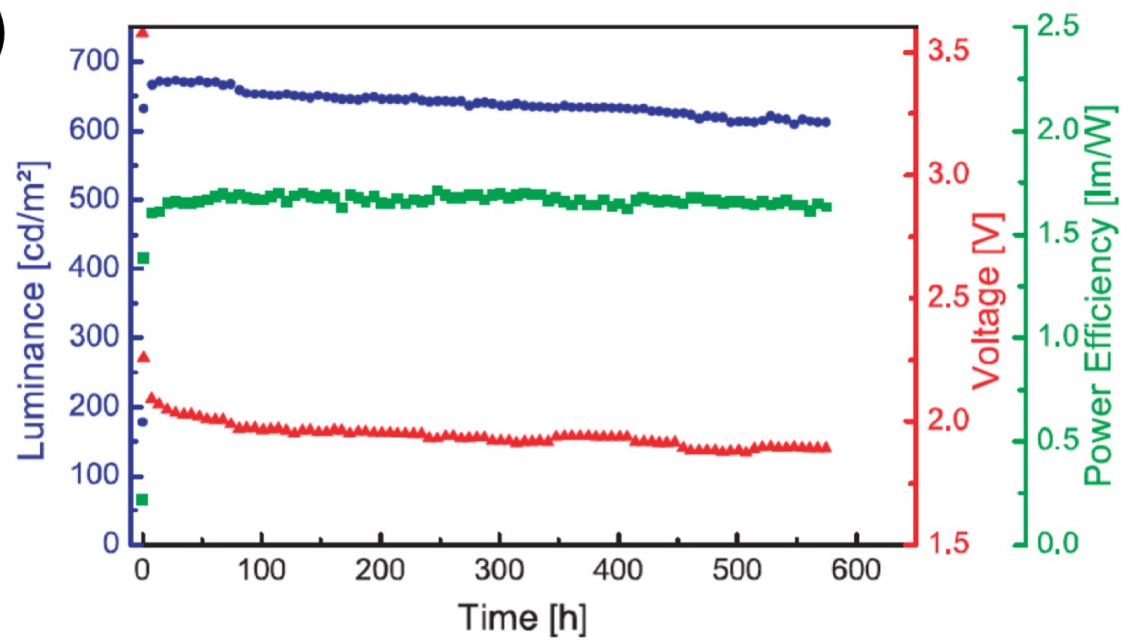

Figure 9. Layout of the LEC and chemical structures of the iTMC and the ionic liquid used in the active layer. Luminance, average voltage and power efficiency versus time for the LEC biased with a pulsed current using a block wave at a frequency of $1000 \mathrm{~Hz}$ and a duty cycle of $30 \%$ with an average current density of $185 \mathrm{~A} \mathrm{~m}^{-2}$. Reprinted (adapted) with permission from (Tordera, D., Meier, S., Lenes, M., Costa, R., Orti, E., Sarfert, W., and Bolink, H., Simple, Fast, Bright, and Stable Light Sources. Advanced Materials, 2012, 24, 897-900). Copyright (2012) WILEY-VCH.

The LEC shown in Figure 9 has the structure of ITO/PEDOT:PSS/Iridium complex:ionic liquid/Al. The active layer consisted of bis(2-phenylpyridine- $C, N)(4-(3,5$-dimethoxyphenyl)-6phenyl-2,2'-bipyridine- $N, N^{\prime}$ )iridium(III) hexafluorophosphate, or [Ir(ppy)2(Meppbpy)][PF6] and the ionic liquid 1-butyl-3-methylimidazolium hexafluorophosphate, $\left[\mathrm{BMIM}^{+}: \mathrm{PF}^{-}\right]$at a molar ratio of 4:1. The LEC exhibited an initial luminance of $670 \mathrm{~cd} / \mathrm{m}^{2}$, which decreased to about 600 $\mathrm{cd} / \mathrm{m}^{2}$ during a continuous operation that lasted nearly 600 hours. A linear extrapolation yielded a T50 lifetime of more than 6,000 hours. Meanwhile, the power efficiency remained nearly constant and the (average) driving voltage decreased from over $3.5 \mathrm{~V}$ to less than $2 \mathrm{~V}$. The excellent stability of this LEC exemplifies several effective strategies that have been commonly adopted in iTMC-LECs. First, the use of a pulsed, current driving scheme. The LEC of Figure 9 
was driven with a pulsed current of $1 \mathrm{kHz}$ and $30 \%$ duty cycle. The average current density was $185 \mathrm{~A} / \mathrm{m}^{2}$, or $18.5 \mathrm{~mA} / \mathrm{cm}^{2}$. The current drive (vs. voltage drive) enabled a fast (less than $1 \mathrm{~s}$ ) turn-on of the cell to reach significant brightness. The pulsed driving scheme was mainly responsible for improved stability vs. a DC current driving scheme, as shown in Figure 9 (d). Second, the addition of an ionic liquid additive improvde the ionic conductivity and response time of the cell. Here, the particular ionic liquid did not adversely affect the stability of the LEC.[148] Third, the use of a PEDOT:PSS layer for efficient hole injection. Long lifetime iTMC-based LECs have also been reported with a modified Ru (bpy) ${ }_{3}{ }^{2+}$ complex, [137,150], several Ir complexes, [145,151,152] BODIPY-porphyrin dyads[126].

\section{Challenges and Opportunities}

Experimental results presented in the preceding sections convey that the operational lifetime of both PLECs and iTMC-LECs have significantly improved in recent years. Longlasting LECs are realized with three general approaches: 1 . An optimized driving scheme to activate the LEC, to fix the LEC junction, and/or to drive the LEC for an extended duration; 2. An optimized LEC active layer that includes the emitting material, the electrolyte material and additives; and 3. Optimized device architecture that includes additional layers such as a holeinjection layer, a light out-coupling film, and/or the encapsulation of the LEC. Most of the longest lasting LECs, i.e., those that lasted at least 1,000 hours when operated continuously,[6,50,52,144,145,152-154] employ all three strategies. These strategies should also be used to optimize future LECs due to their proven effectiveness.

Increasing the operating lifetime of LECs by another one or two orders of magnitude, however, represents a major challenge. In PLECs, an increase in driving voltage, as shown in Figures 2, 5 and 8, is an often-overlooked degradation behavior. When the PLEC is driven by a constant current, an increase in driving voltage indicates an increase in the overall resistance of the cell. When the driving voltage becomes too high, rapid device destruction occurs.[49,58] In LECs, a high operating voltage can result in not only Joule heating or a dielectric breakdown, but also runaway electrochemical reactions. It is therefore, important to understand the cause of a driving voltage drift in PLECs. An unexpected observation might provide important clues. In ITO/MEH-PPV:PEO:LiTf/Al LECs with $20 \%$ electrolyte loading such as the one shown in Figure 5, a negative (reverse bias) current stress yielded peak luminance that tripled that reached in a positive current stress. [58] The reverse bias operation, however, was less stable due to a 
rapidly increasing driving voltage. When the applied reverse bias current was $83.3 \mathrm{~mA} / \mathrm{cm}^{2}$, the luminance decay completely decouples from the driving voltage, as shown in Figure 10. For over 200 hours, the cell luminance stayed nearly constant between $451 \mathrm{~cd} / \mathrm{m}^{2}$ and $486 \mathrm{~cd} / \mathrm{m}^{2}$. The driving voltage, however, increased rapidly during the same period and was likely to cause catastrophic device failure due to the level reached. These strange results suggest that the doping profile (p-dominant vs. $n$-dominant) plays a major role in the stability of the driving voltage.

Therefore, it is important to consider both luminance decay and a driving voltage increase in any assessment of the stability of PLECs. In particular, when an extrapolated lifetime is determined, the driving voltage should also be considered. When an apparent luminance decay is caused by PL quenching, a driving voltage is a more reliable marker of true device degradation.[45]

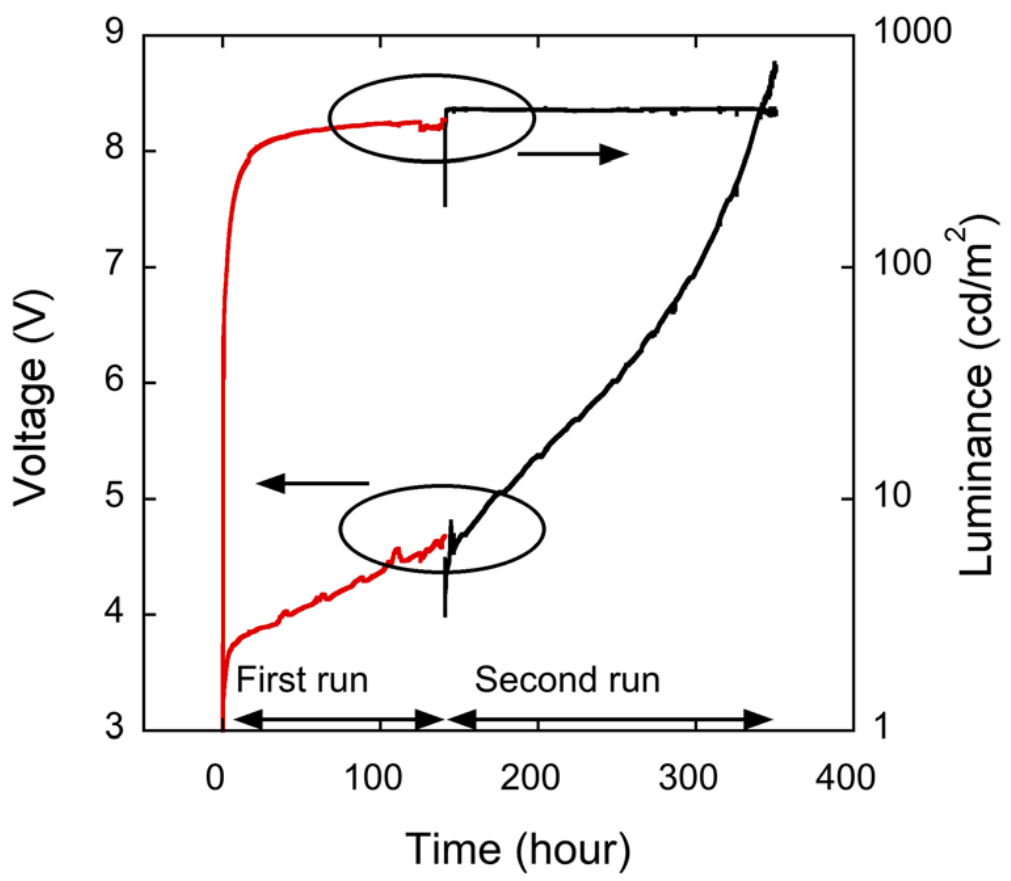

Figure 10. Time evolution of luminance and operating voltage of a ITO/MEHPPV: PEO:LiTf/Al sandwich LEC operated under a constant current of $-10 \mathrm{~mA}$ (reverse bias). The cell is run twice with an idling period of approximately 4 days after the first run. Reprinted (adapted) with permission from (Gao, J. and AlTal, F., Decoupled luminance decay and voltage drift in polymer light-emitting electrochemical cells: Forward bias vs. reverse bias operation. Applied Physics Letters 2014, 104, 143301). Copyright (2014) American Institute of Physics.

Interestingly, driving voltage increases have not been observed in some long-life iTMC LECs, as shown in Figure 8 and other studies.[145,155] When driven with a constant voltage bias, the cell current is observed to increase for over 1,000 hours.[144,152,154] This behavior has been attributed to the very low ionic mobility in these devices, causing them to experience a 
prolonged activation process that obscures the decay process. Nevertheless, a stable or decreasing driving voltage represents a major advantage of iTMC-based LECs over PLECs when both are operated at RT.

The LECs with a 1,000-hour operating lifetime were all operated at low or moderate current densities. The peak luminance of these devices, however, was no less than $100 \mathrm{~cd} / \mathrm{m}^{2}$. This means that these long-lasting LECs were also very efficient. For example, a yellow-emitting PLEC operated for 1,400 hours had a power efficiency of $18.1 \mathrm{~lm} / \mathrm{W}$ and a current efficiency of $14.6 \mathrm{Cd} / \mathrm{A}$ (measured at $0.77 \mathrm{~mA} / \mathrm{cm}^{2}$ on a champion device). This high efficiency allowed for the PLEC to operate at a very low current density of $1.9 \mathrm{~mA} / \mathrm{cm}^{2}$ while reaching a peak luminance of about $200 \mathrm{~cd} / \mathrm{m}^{2}$. The LEC efficiency, however, is still an order of magnitude lower than the state-of-the-art PLEDs of CDT. Although efficiency and operating lifetime are separate figures of merit concerning light-emitting devices, they appear to be closely related in LECs. Improving the efficiency, at least for PLECs, is a challenging but highly plausible route to a 10,000-hour continuous operation lifetime.

The various LEC materials can also be combined to exploit the excellent film-forming ability of polymers, the high intrinsic efficiencies of iTMCs, and the easy color tenability of small molecules and quantum dots. Indeed, hybrid LECs have been reported based on the composites of CP/QD [131], iTMC/QD,[130] SM/iTMC,[156]Polymer/iTMC[157], and PEO/iTMC[146]. Finally, novel device structures can be explored to benefit both the understanding of fundamental LEC processes and device performance. For example, LECs with coated or dispersed bipolar electrodes exhibit orders of magnitude improvement in both response times and light output due to the formation of a large-area, highly emissive "bulk homojunction." $[158,159]$ It would be challenging but extremely interesting to see whether the concept of bulk homojunction can be applied to sandwich LECs, although plasmonic enhancement of EL has been reported in iTMC-LECs with added gold nanoparticles.[160] At present, stacked tandem cells have been demonstrated with enhanced efficiencies or white light emission.[161-163] Significantly, when a tandem cell is operated at the same brightness as a single-layered cell made with the same emitter, it exhibits much-improved (by up to $50 \%$ ) operational lifetime compared to the latter. This is due to the tandem cell's higher external quantum efficiency, which allows it to be operated at approximately $60 \%$ of the current density of the single-layered cell to reach the same peak luminance of about $300 \mathrm{~cd} / \mathrm{m}^{2} .[161]$ 


\section{Conclusions and outlook}

The operation lifetime of PLECs and iTMC-LECs has been surveyed. Recent advances in materials and device design have led to an operating lifetime exceeding 1,000 hours. By examining the various factors affecting the LEC operating lifetime, three general strategies have been identified as responsible for the marked improvement over early LECs. These three strategies include an optimized driving scheme, an optimized LEC active layer, and an optimized device structure. An upwardly drifting operating voltage is a major challenge in PLECs under the stress of a constant current. On the other hand, a significant portion of the luminance decay observed in PLECs is caused by a reversible doping process and is largely recoverable. Also, planar PLECs with a cryogenically fixed junction exhibit similar redox stability to a PLED made with the same luminescent polymer. To further improve the operating lifetime of LECs for practical applications, the devices must be significantly more efficient. New materials, along with innovative device structures will be the most effective way forward.

\section{ACKNOWLEDGMENT}

The research at Queen's University was supported by the Natural Sciences and Engineering Research Council of Canada (NSERC).

\section{References}

1. Tang S, Edman L: Light-Emitting Electrochemical Cells: A Review on Recent Progress. Topics in Current Chemistry 2016, 374.

2. Fresta $E$, Costa RD: Beyond traditional light-emitting electrochemical cells - a review of new device designs and emitters. Journal of Materials Chemistry C 2017, 5:5643-5675.

3. Gao J: Polymer light-emitting electrochemical cells-Recent advances and future trends. Current opinion in Electrochemistry 2018, 7:87-94.

4. Tang S, Murto P, Xu X, Larsen C, Wang E, Edman L: Intense and Stable Near-Infrared Emission from Light-Emitting Electrochemical Cells Comprising a Metal-Free Indacenodithieno[3,2-b]thiophene-Based Copolymer as the Single Emitter. Chemistry of Materials 2017, 29:7750-7759.

5. Zimmermann J, Jurgensen N, Morfa AJ, Wang BH, Tekoglu S, Hernandez-Sosa G: Poly(lacticco-glycolic acid) (PLGA) as lon-Conducting Polymer for Biodegradable Light-Emitting Electrochemical Cells. Acs Sustainable Chemistry \& Engineering 2016, 4:7050-7055. 
6. Mindemark J, Tang S, Wang J, Kaihovirta N, Brandell D, Edman L: High-Performance LightEmitting Electrochemical Cells by Electrolyte Design. Chemistry of Materials 2016, 28:2618-2623.

7. Zhang ZT, Guo KP, Li YM, Li XY, Guan GZ, Li HP, Luo YF, Zhao FY, Zhang Q, Wei B, et al.: A colour-tunable, weavable fibre-shaped polymer light-emitting electrochemical cell. Nature Photonics 2015, 9:233-238.

8. Xiong Y, Li L, Liang J, Gao H, Chou S, Pei Q: Efficient white polymer light-emitting electrochemical cells. Materials Horizons 2015, 2:338-343.

9. Nishikitani Y, Takizawa D, Nishide H, Uchida S, Nishimura S: White Polymer Light-Emitting Electrochemical Cells Fabricated Using Energy Donor and Acceptor Fluorescent piConjugated Polymers Based on Concepts of Band-Structure Engineering. Journal of Physical Chemistry C 2015, 119:28701-28710.

10. Sakanoue T, Yonekawa F, Albrecht K, Yamamoto K, Takenobu T: An Ionic Liquid That Dissolves Semiconducting Polymers: A Promising Electrolyte for Bright, Efficient, and Stable Light-Emitting Electrochemical Cells. Chemistry of Materials 2017, 29:6122-6129.

11. Gozzi G, Cagnani LD, Faria RM, Santos LF: Electrical properties of electrochemically doped organic semiconductors using light-emitting electrochemical cells. Journal of Solid State Electrochemistry 2016, 20:2127-2133.

12. Jenatsch S, Wang L, Leclaire N, Hack E, Steim R, Anantharaman SB, Heier J, Ruhstaller B, Penninck $L$, Nuesch F, et al.: Visible light-emitting host-guest electrochemical cells using cyanine dyes. Organic Electronics 2017, 48:77-84.

13. Subeesh MS, Shanmugasundaram K, Sunesh CD, Chitumalla RK, Fang J, Choe Y: Host-Dopant System To Generate Bright Electroluminescence from Small Organic Molecule Functionalized Light-Emitting Electrochemical Cells. Journal of Physical Chemistry $C$ 2016, 120:12207-12217.

14. Shanmugasundaram K, Subeesh MS, Sunesh CD, Choe Y: Non-doped deep blue lightemitting electrochemical cells from charged organic small molecules. Rsc Advances 2016, 6:28912-28918.

15. Zeng QY, Li FS, Guo TL, Shan GG, Su ZM: Synthesis of red-emitting cationic Ir (III) complex and its application in white light-emitting electrochemical cells. Organic Electronics 2017, 42:303-308.

16. Zeng QY, Li FS, Guo TL, Shan GG, Su ZM: Large Size Color-tunable Electroluminescence from Cationic Iridium Complexes-based Light-emitting Electrochemical Cells. Scientific Reports 2016, 6.

17. Wu J, Li F, Zeng Q, Nie C, Ooi PC, Guo T, Shan G, Su Z: Flexible blue-green and white lightemitting electrochemical cells based on cationic iridium complex. Organic Electronics 2016, 28:314-318.

18. Suhr KJ, Bastatas LD, Shen YL, Mitchell LA, Holliday BJ, Slinker JD: Enhanced Luminance of Electrochemical Cells with a Rationally Designed Ionic Iridium Complex and an Ionic Additive. Acs Applied Materials \& Interfaces 2016, 8:8888-8892.

19. Ross DAW, Scattergood PA, Babaei A, Pertegas A, Bolink HJ, Elliott PIP: Luminescent osmium(II) bi-1,2,3-triazol-4-yl complexes: photophysical characterisation and application in light-emitting electrochemical cells. Dalton Transactions 2016, 45:77487757. 
20. Lepeltier M, Graff B, Lalevee J, Wantz G, Ibrahim-Ouali M, Gigmes D, Dumur F: Heteroleptic iridium (III) complexes with three different ligands: Unusual triplet emitters for lightemitting electrochemical cells. Organic Electronics 2016, 37:24-34.

21. Zanoni KPS, Sanematsu MS, Iha NYM: Photophysical characterization of Ir(ppy)(2)(dmb) PF6 towards application in light-emitting electrochemical cells (LECs). Inorganic Chemistry Communications 2014, 43:162-164.

22. Di Marcantonio M, Gellner S, Namanga JE, Frohleiks J, Gerlitzki N, Vollkommer F, Bacher G, Nannen E: Performance Enhancement by ZnO Nanoparticle Layer in Hybrid lonic Transition Metal Complex-Light-Emitting Electrochemical Cells (iTMC-LECs). Advanced Materials Technologies 2017, 2.

23. Sandstrom A, Edman L: Towards High-Throughput Coating and Printing of Light-Emitting Electrochemical Cells: A Review and Cost Analysis of Current and Future Methods. Energy Technology 2015, 3:329-339.

24. Sato K, Uchida S, Toriyama S, Nishimura S, Oyaizu K, Nishide H, Nishikitani Y: Low-Cost, Organic Light-Emitting Electrochemical Cells with Mass-Producible Nanoimprinted Substrates Made Using Roll-to-Roll Methods. Advanced Materials Technologies 2017, 2.

25. Pei QB, Yu G, Zhang C, Yang Y, Heeger AJ: Polymer Light-Emitting Electrochemical-Cells. Science 1995, 269:1086-1088.

26. Pei Q, Yang Y, Yu G, Zhang C, Heeger AJ: Polymer Light-Emitting Electrochemical Cells: In Situ Formation of a Light-Emitting p-n Junction. Journal of the American Chemical Society 1996, 118:3922-3929.

27. Jafari MJ, Liu J, Engquist I, Ederth T: Time-Resolved Chemical Mapping in Light-Emitting Electrochemical Cells. Acs Applied Materials \& Interfaces 2017, 9:2747-2757.

28. AlTal F, Gao J: Charging and discharging of a planar polymer light-emitting electrochemical cell. Electrochimica Acta 2016, 220:529-535.

29. Lanz T, Lindh EM, Edman L: On the asymmetric evolution of the optical properties of a conjugated polymer during electrochemical p- and n-type doping. Journal of Materials Chemistry C 2017, 5:4706-4715.

30. Altal F, Gao J: High resolution scanning optical imaging of a frozen planar polymer lightemitting electrochemical cell: an experimental and modelling study. Science ChinaChemistry 2017, 60:497-503.

31. AlTal F, Gao J: High resolution scanning optical imaging of a frozen polymer p-n junction. Journal of Applied Physics 2016, 120:115501.

32. Gao J, Chen S, AlTal F, Hu S, Wantz G, Bouffier L: Bipolar Electrode Array Embedded in a Polymer Light-Emitting Electrochemical Cell. Acs Applied Materials \& Interfaces 2017, 9:32405-32410.

33. Hu SY, Chi X, Chen SL, AITal F, Gao J: Visualizing the Bipolar Electrochemistry of Electrochemically Doped Luminescent Conjugated Polymers. Journal of Physical Chemistry C 2017, 121:8409-8415.

34. Yamada T: Latest development of polymer light-emitting material for printed OLED. Edited by; 2016. vol 2017.]

35. Cao Y, Yu G, Heeger AJ, Yang CY: Efficient, fast response light-emitting electrochemical cells: Electroluminescent and solid electrolyte polymers with interpenetrating network morphology. Applied Physics Letters 1996, 68:3218-3220. 
36. Yang Y, Pei QB: Efficient blue-green and white light-emitting electrochemical cells based on poly 9,9-bis(3,6-dioxaheptyl)-fluorene-2,7-diyl. Journal of Applied Physics 1997, 81:3294-3298.

37. Cao Y, Pei QB, Andersson MR, Yu G, Heeger AJ: Light-emitting electrochemical cells with crown ether as solid electrolyte. Journal of the Electrochemical Society 1997, 144:L317L320.

38. Gao J, Li Y, Yu G, Heeger AJ: Polymer light-emitting electrochemical cells with frozen junctions. Journal of Applied Physics 1999, 86:4594.

39. Edman L, Moses D, Heeger AJ: Influence of the anion on the kinetics and stability of a lightemitting electrochemical cell. Synthetic Metals 2003, 138:441-446.

40. Shao Y, Bazan GC, Heeger AJ: Long-Lifetime Polymer Light-Emitting Electrochemical Cells. Advanced Materials 2007, 19:365-370.

41. Yu Z, Sun M, Pei Q: Electrochemical Formation of Stable p-i-n Junction in Conjugated Polymer Thin Films. The Journal of Physical Chemistry B 2009, 113:8481-8486.

42. Yu ZB, Wang ML, Lei GT, Liu J, Li L, Pei QB: Stabilizing the Dynamic p-i-n Junction in Polymer Light-Emitting Electrochemical Cells. Journal of Physical Chemistry Letters 2011, 2:367372.

43. Li X, AlTal F, Liu G, Gao J: Long-term, intermittent testing of sandwich polymer lightemitting electrochemical cells. Applied Physics Letters 2013, 103:243304.

44. Jurgensen N, Zimmermann J, Morfa AJ, Hernandez-Sosa G: Biodegradable Polycaprolactone as Ion Solvating Polymer for Solution-Processed Light-Emitting Electrochemical Cells. Scientific Reports 2016, 6.

45. AlTal F, Gao J: Long-term testing of polymer light-emitting electrochemical cells: Reversible doping and black spots. Organic Electronics 2015, 18:1-7.

46. Shao Y, Gong X, Heeger AJ, Liu M, Jen AKY: Long-Lifetime Polymer Light-Emitting Electrochemical Cells Fabricated with Crosslinked Hole-Transport Layers. Advanced Materials 2009, 21:1972-1975.

47. Asadpoordarvish A, Sandstrom A, Tang S, Granstrom J, Edman L: Encapsulating lightemitting electrochemical cells for improved performance. Applied Physics Letters 2012, 100:193508.

48. Tang S, Pan J, Buchholz HA, Edman L: White Light from a Single-Emitter Light-Emitting Electrochemical Cell. Journal of the American Chemical Society 2013, 135:3647-3652.

49. Jang JH, Kim LH, Jeong YJ, Kim K, An TK, Kim SH, Park CE: Accelerated lifetime test based on general electrical principles for light-emitting electrochemical cells. Organic Electronics 2016, 34:50-56.

50. Fang J, Matyba P, Edman L: The Design and Realization of Flexible, Long-Lived LightEmitting Electrochemical Cells. Advanced Functional Materials 2009, 19:2671-2676.

51. Sandstrom A, Matyba $P$, Edman L: Yellow-green light-emitting electrochemical cells with long lifetime and high efficiency. Applied Physics Letters 2010, 96:053303.

52. Tang S, Edman L: Quest for an Appropriate Electrolyte for High-Performance Light-Emitting Electrochemical Cells. Journal of Physical Chemistry Letters 2010, 1:2727-2732.

53. Tang S, Pan J, Buchholz H, Edman L: White Light-Emitting Electrochemical Cell. Acs Applied Materials \& Interfaces 2011, 3:3384-3388. 
54. Asadpoordarvish A, Sandstrom A, Edman L: A Flexible Encapsulation Structure for AmbientAir Operation of Light-Emitting Electrochemical Cells. Advanced Engineering Materials 2016, 18:105-110.

55. Xiong Y, Li L, Liang JJ, Gao H, Chou SY, Pei QB: Efficient white polymer light-emitting electrochemical cells. Materials Horizons 2015, 2:338-343.

56. Walker CW, Salomon M: IMPROVEMENT OF IONIC-CONDUCTIVITY IN PLASTICIZED PEOBASED SOLID POLYMER ELECTROLYTES. Journal of the Electrochemical Society 1993, 140:3409-3412.

57. Parker ID, Cao Y, Yang CY: Lifetime and degradation effects in polymer light-emitting diodes. Journal of Applied Physics 1999, 85:2441-2447.

58. Gao J, AlTal F: Decoupled luminance decay and voltage drift in polymer light-emitting electrochemical cells: Forward bias vs. reverse bias operation. Applied Physics Letters 2014, 104:143301.

59. Rahman MYA, Ahmad A, Umar AA, Taslim R, Su'ait MS, Salleh MM: Polymer electrolyte for photoelectrochemical cell and dye-sensitized solar cell: a brief review. Ionics 2014, 20:1201-1205.

60. Hallinan DT, Balsara NP: Polymer Electrolytes. Annual Review of Materials Research, Vol 43 2013, 43:503-+.

61. Bruce PG, Vincent CA: POLYMER ELECTROLYTES. Journal of the Chemical Society-Faraday Transactions 1993, 89:3187-3203.

62. Gao J, Yu G, Heeger AJ: Polymer light-emitting electrochemical cells with frozen p-i-n junction. Applied Physics Letters 1997, 71:1293-1295.

63. Dane J, Tracy C, Gao J: Direct observation of a frozen junction in polymer light-emitting electrochemical cells. Applied Physics Letters 2005, 86:153509.

64. Dane J, Gao J: Imaging the degradation of polymer light-emitting devices. Applied Physics Letters 2004, 85:3905-3907.

65. Zhang Y, Gao J: Lifetime study of polymer light-emitting electrochemical cells. Journal of Applied Physics 2006, 100:084501.

66. Yu G, Cao Y, Andersson M, Gao J, Heeger AJ: Polymer Light-Emitting Electrochemical Cells with Frozen p-i-n Junction at Room Temperature. Advanced Materials 1998, 10:385388.

67. Edman L, Pauchard M, Moses D, Heeger AJ: Planar polymer light-emitting device with fast kinetics at a low voltage. Journal of Applied Physics 2004, 95:4357-4361.

68. Edman L, Pauchard M, Liu B, Bazan G, Moses D, Heeger AJ: Single-component light-emitting electrochemical cell with improved stability. Applied Physics Letters 2003, 82:39613963.

69. Wantz G, Gautier B, Dumur F, Phan TNT, Gigmes D, Hirsch L, Gao J: Towards frozen organic PN junctions at room temperature using high-Tg polymeric electrolytes. Organic Electronics 2012, 13:1859-1864.

70. Yu Z, Li L, Gao H, Pei Q: Polymer light-emitting electrochemical cells: Recent developments to stabilize the $p-i-n$ junction and explore novel device applications. Science China Chemistry 2013, 56:1075-1086.

71. Leger JM, Rodovsky DB, Bartholomew GP: Self-Assembled, Chemically Fixed Homojunctions in Semiconducting Polymers. Advanced Materials 2006, 18:3130-3134. 
72. Leger JM, Patel DG, Rodovsky DB, Bartholomew GP: Polymer Photovoltaic Devices Employing a Chemically Fixed p-i-n Junction. Advanced Functional Materials 2008, 18:1212-1219.

73. Kosilkin IV, Martens MS, Murphy MP, Leger JM: Polymerizable Ionic Liquids for FixedJunction Polymer Light-Emitting Electrochemical Cells. Chemistry of Materials 2010, 22:4838-4840.

74. Pingree LSC, Rodovsky DB, Coffey DC, Bartholomew GP, Ginger DS: Scanning Kelvin Probe Imaging of the Potential Profiles in Fixed and Dynamic Planar LECs. Journal of the American Chemical Society 2007, 129:15903-15910.

75. Tang S, Irgum K, Edman L: Chemical stabilization of doping in conjugated polymers. Organic Electronics 2010, 11:1079-1087.

76. Tang S, Edman L: On-demand photochemical stabilization of doping in light-emitting electrochemical cells. Electrochimica Acta 2011, 56:10473-10478.

77. Hoven CV, Wang HP, Elbing M, Garner L, Winkelhaus D, Bazan GC: Chemically fixed p-n heterojunctions for polymer electronics by means of covalent B-F bond formation. Nature Materials 2010, 9:249-252.

78. Horhold HH, Tillmann H, Bader C, Stockmann R, Nowotny J, Klemm E, Holzer W, Penzkofer A: MEH-PPV and dialkoxy phenylene vinylene copolymers. Synthesis and lasing characterization. Synthetic Metals 2001, 119:199-200.

79. Liu J, Guo TF, Yang Y: Effects of thermal annealing on the performance of polymer light emitting diodes. Journal of Applied Physics 2002, 91:1595-1600.

80. Gautier B, Gao J: Polymer light-emitting devices based on a polymer/salt mixture. Applied Physics Letters 2012, 101:093302.

81. Gautier B, Wu XM, Altal F, Chen SL, Gao J: Reverse bias activation of salt-doped polymer light-emitting devices. Organic Electronics 2016, 28:47-52.

82. Li X, Gao J, Liu G: Reversible luminance decay in polymer light-emitting electrochemical cells. Applied Physics Letters 2013, 102:223303.

83. Li XY, AlTal F, Liu GJ, Gao J: Long-term, intermittent testing of sandwich polymer lightemitting electrochemical cells. Applied Physics Letters 2013, 103:243304.

84. Yu G, Cao Y, Zhang C, Li Y, Gao J, Heeger AJ: Complex admittance measurements of polymer light-emitting electrochemical cells: Ionic and electronic contributions. Applied Physics Letters 1998, 73:111-113.

85. Sakanoue T, Li JP, Tanaka H, Ito R, Ono S, Kuroda S, Takenobu T: High Current Injection into Dynamic p-n Homojunction in Polymer Light-Emitting Electrochemical Cells. Advanced Materials 2017, 29.

86. Li YF, Cao Y, Gao J, Wang DL, Yu G, Heeger AJ: Electrochemical properties of luminescent polymers and polymer light-emitting electrochemical cells. Synthetic Metals 1999, 99:243-248.

87. Holt AL, Leger JM, Carter SA: Solid-state electrochromic devices based on poly (phenylene vinylene) polymers. Applied Physics Letters 2005, 86.

88. Hu Y, Gao J: Cationic effects in polymer light-emitting electrochemical cells. Applied Physics Letters 2006, 89. 
89. Hohertz D, Gao J: How Electrode Work Function Affects Doping and Electroluminescence of Polymer Light-Emitting Electrochemical Cells. Advanced Materials 2008, 20:32983302.

90. Li XY, Gao J, Liu GJ: Thickness dependent device characteristics of sandwich polymer lightemitting electrochemical cell. Organic Electronics 2013, 14:1441-1446.

91. van Reenen S, Matyba P, Dzwilewski A, Janssen RAJ, Edman L, Kemerink M: Salt Concentration Effects in Planar Light-Emitting Electrochemical Cells. Advanced Functional Materials 2011, 21:1795-1802.

92. Shin JH, Matyba P, Robinson ND, Edman L: The influence of electrodes on the performance of light-emitting electrochemical cells. Electrochimica Acta 2007, 52:6456-6462.

93. Matyba P, Andersson MR, Edman L: On the desired properties of a conjugated polymerelectrolyte blend in a light-emitting electrochemical cell. Organic Electronics 2008, 9:699-710.

94. Fang J, Matyba $P$, Robinson ND, Edman L: Identifying and alleviating electrochemical sidereactions in light-emitting electrochemical cells. Journal of the American Chemical Society 2008, 130:4562-4568.

95. Tang S, Mindemark J, Araujo CMG, Braudell D, Edman L: Identifying Key Properties of Electrolytes for Light-Emitting Electrochemical Cells. Chemistry of Materials 2014, 26:5083-5088.

96. Alem S, Gao J: The effect of annealing/quenching on the performance of polymer lightemitting electrochemical cells. Organic Electronics 2008, 9:347-354.

97. Yang $\mathrm{CH}$, Sun QJ, Qiao J, Li YF: Ionic liquid doped polymer light-emitting electrochemical cells. Journal of Physical Chemistry B 2003, 107:12981-12988.

98. Panozzo S, Armand $M$, Stephan O: Light-emitting electrochemical cells using a molten delocalized salt. Applied Physics Letters 2002, 80:679-681.

99. Ouisse T, Armand M, Kervella Y, Stephan O: Fully transparent, organic light-emitting electrochemical cells. Applied Physics Letters 2002, 81:3131-3133.

100. Habrard F, Ouisse T, Stephan O: Conjugated polymer/molten salt blend optimization. Journal of Physical Chemistry B 2006, 110:15049-15051.

101. Marcilla R, Mecerreyes D, Winroth G, Brovelli S, Yebra MdMR, Cacialli F: Light-emitting electrochemical cells using polymeric ionic liquid/polyfluorene blends as luminescent material. Applied Physics Letters 2010, 96.

102. Holzer L, Winkler B, Wenzl FP, Tasch S, Dai L, Mau AWH, Leising G: Light-emitting electrochemical cells and light-emitting diodes based on ionic conductive poly(phenylene vinylene): a new chemical sensor system. Synthetic Metals 1999, 100:71-77.

103. Morgado J, Friend RH, Cacialli F, Chuah BS, Moratti SC, Holmes AB: Light-emitting devices based on a poly(p-phenylene vinylene) derivative with ion-coordinating side groups. Journal of Applied Physics 1999, 86:6392-6395.

104. Morgado J, Cacialli F, Friend RH, Chuah BS, Rost $H$, Holmes AB: Light-emitting devices based on a poly(p-phenylenevinylene) statistical copolymer with oligo(ethylene oxide) side groups. Macromolecules 2001, 34:3094-3099. 
105. Morgado J, Friend RH, Cacialli F, Chuah BS, Rost H, Moratti SC, Holmes AB: Light-emitting electrochemical cells based on poly(p-phenylene vinylene) copolymers with iontransporting side groups. Synthetic Metals 2001, 122:111-113.

106. Kong F, Wu XL, Zheng Y, Ou CG, Yuan RK, Yang CZ, Chu PK: Optical and electrical properties of single-ion transport light-emitting electrochemical cells. Journal of Applied Physics 2006, 99.

107. Johansson T, Mammo W, Andersson MR, Inganas O: Light-emitting electrochemical cells from oligo(ethylene oxide)-substituted polythiophenes: Evidence for in situ doping. Chemistry of Materials 1999, 11:3133-3139.

108. Stephan O, Collomb V, Vial JC, Armand M: Blue-green light-emitting diodes and electrochemical cells based on a copolymer derived from fluorene. Synthetic Metals 2000, 113:257-262.

109. Sun M, Zhong C, Yu Z, Cao Y, Pei Q: Fluorene-Benzothiadiazole Copolymer for Single Component Green Light-Emitting Electrochemical Cells. Journal of Display Technology 2013, 9:476-482.

110. Sun QJ, Wang HQ, Yang CH, He GF, Li YF: Blue-green light-emission LECs based on block copolymers containing di(alpha-naphthalene vinylene)benzene chromophores and tri(ethylene oxide) spacers. Synthetic Metals 2002, 128:161-165.

111. Sun QJ, Wang HQ, Yang CH, Wang XG, Liu DS, Li YF: Polymer light-emitting electrochemical cells with the block copolymers containing PEO segments. Thin Solid Films 2002, 417:14-19.

112. Sun QJ, Wang HQ, Yang CH, Li YF: Synthesis and electroluminescence of novel copolymers containing crown ether spacers. Journal of Materials Chemistry 2003, 13:800-806.

113. Ko HC, Lim DK, Kim SH, Choi W, Lee H: Light-emitting electrochemical cells based on polyimide containing perylene and tri(ethylene oxide) moieties. Synthetic Metals 2004, 144:177-182.

114. Cimrova V, Schmidt W, Rulkens R, Schulze M, Meyer W, Neher D: Efficient blue light emitting devices based on rigid-rod polyelectrolytes. Advanced Materials 1996, 8:585\&.

115. Huang F, Wu HB, Wang D, Yang W, Cao Y: Novel electroluminescent conjugated polyelectrolytes based on polyfluorene. Chemistry of Materials 2004, 16:708-716.

116. Huang F, Hou LT, Shen HL, Yang RQ, Hou Q, Cao Y: Synthesis and optical and electroluminescent properties of novel conjugated polyelectrolytes and their neutral precursors derived from fluorene and benzoselenadiazole. Journal of Polymer Science Part a-Polymer Chemistry 2006, 44:2521-2532.

117. Gu Z, Bao YJ, Zhang Y, Wang M, Shen QD: Anionic water-soluble poly(phenylenevinylene) alternating copolymer: High-efficiency photoluminescence and dual electroluminescence. Macromolecules 2006, 39:3125-3131.

118. Gu Z, Shen QD, Zhang J, Yang CZ, Bao YJ: Dual electroluminescence from a singlecomponent light-emitting electrochemical cell, based on water-soluble conjugated polymer. Journal of Applied Polymer Science 2006, 100:2930-2936.

119. Edman L, Liu B, Vehse M, Swensen J, Bazan GC, Heeger AJ: Single-component lightemitting electrochemical cell fabricated from cationic polyfluorene: Effect of film morphology on device performance. Journal of Applied Physics 2005, 98. 
120. Chen FC, Yang Y, Pei Q: Phosphorescent light-emitting electrochemical cell. Applied Physics Letters 2002, 81:4278-4280.

121. Hill ZB, Rodovsky DB, Leger JM, Bartholomew GP: Synthesis and utilization of perylenebased $n$-type small molecules in light-emitting electrochemical cells. Chemical Communications 2008:6594-6596.

122. Tang S, Tan W-Y, Zhu X-H, Edman L: Small-molecule light-emitting electrochemical cells: evidence for in situ electrochemical doping and functional operation. Chemical Communications 2013, 49:4926-4928.

123. Subeesh MS, Shanmugasundaram K, Sunesh CD, Nguyen TP, Choe Y: Phenanthroimidazole Derivative as an Easily Accessible Emitter for Non-Doped Light-Emitting Electrochemical Cells. Journal of Physical Chemistry C 2015, 119:23676-23684.

124. Chen H-F, Liao C-T, Chen T-C, Su H-C, Wong K-T, Guo T-F: An ionic terfluorene derivative for saturated deep-blue solid state light-emitting electrochemical cells. Journal of Materials Chemistry 2011, 21:4175-4181.

125. Ayguler MF, Weber MD, Puscher BMD, Medina DD, Docampo P, Costa RD: Light-Emitting Electrochemical Cells Based on Hybrid Lead Halide Perovskite Nanoparticles. Journal of Physical Chemistry C 2015, 119:12047-12054.

126. Weber MD, Nikolaou V, Wittmann JE, Nikolaou A, Angaridis PA, Charalambidis G, Stangel C, Kahnt A, Coutsolelos AG, Costa RD: Benefits of using BODIPY-porphyrin dyads for developing deep-red lighting sources. Chemical Communications 2016, 52:1602-1605.

127. Pertegas A, Tordera D, Serrano-Perez JJ, Orti E, Bolink HJ: Light-Emitting Electrochemical Cells Using Cyanine Dyes as the Active Components. Journal of the American Chemical Society 2013, 135:18008-18011.

128. Subeesh MS, Shanmugasundaram K, Sunesh CD, Won YS, Choe Y: Utilization of a phenanthroimidazole based fluorophore in light-emitting electrochemical cells. Journal of Materials Chemistry C 2015, 3:4683-4687.

129. Qian G, Lin Y, Wantz G, Davis AR, Carter KR, Watkins JJ: Saturated and Multi-Colored Electroluminescence from Quantum Dots Based Light Emitting Electrochemical Cells. Advanced Functional Materials 2014, 24:4484-4490.

130. Frohleiks J, Wepfer S, Kelestemur Y, Demir HV, Bacher G, Nannen E: Quantum Dot/LightEmitting Electrochemical Cell Hybrid Device and Mechanism of Its Operation. Acs Applied Materials \& Interfaces 2016, 8:24692-24698.

131. Bader AJN, Ilkevich AA, Kosilkin IV, Leger JM: Precise Color Tuning via Hybrid LightEmitting Electrochemical Cells. Nano Letters 2011, 11:461-465.

132. Zhang HM, Lin H, Liang CJ, Liu H, Liang JJ, Zhao Y, Zhang WG, Sun MJ, Xiao WK, Li H, et al.: Organic-Inorganic Perovskite Light-Emitting Electrochemical Cells with a Large Capacitance. Advanced Functional Materials 2015, 25:7226-7232.

133. Slinker JD, Rivnay J, Moskowitz JS, Parker JB, Bernhard S, Abruna HD, Malliaras GG: Electroluminescent devices from ionic transition metal complexes. Journal of Materials Chemistry 2007, 17:2976-2988.

134. Su HC, Cheng CY: Recent Advances in Solid-State White Light-Emitting Electrochemical Cells. Israel Journal of Chemistry 2014, 54:855-866. 
135. Meier SB, Tordera D, Pertegas A, Roldan-Carmona C, Orti E, Bolink HJ: Light-emitting electrochemical cells: recent progress and future prospects. Materials Today 2014, 17:217-223.

136. Costa RD, Orti E, Bolink HJ: Recent advances in light-emitting electrochemical cells. Pure and Applied Chemistry 2011, 83:2115-2128.

137. Rudmann H, Shimada S, Rubner MF: Solid-state light-emitting devices based on the trischelated ruthenium(II) complex. 4. High-efficiency light-emitting devices based on derivatives of the tris(2,2 '-bipyridyl) ruthenium(II) complex. Journal of the American Chemical Society 2002, 124:4918-4921.

138. Slinker J, Bernards D, Houston PL, Abruna HD, Bernhard S, Malliaras GG: Solid-state electroluminescent devices based on transition metal complexes. Chemical Communications 2003:2392-2399.

139. Hu T, He L, Duan L, Qiu Y: Solid-state light-emitting electrochemical cells based on ionic iridium(III) complexes. Journal of Materials Chemistry 2012, 22:4206-4215.

140. van Reenen S, Akatsuka T, Tordera D, Kemerink M, Bolink HJ: Universal Transients in Polymer and Ionic Transition Metal Complex Light-Emitting Electrochemical Cells. Journal of the American Chemical Society 2013, 135:886-891.

141. Meier SB, van Reenen S, Lefevre B, Hartmann D, Bolink HJ, Winnacker A, Sarfert W, Kemerink M: Dynamic Doping in Planar Ionic Transition Metal Complex-Based LightEmitting Electrochemical Cells. Advanced Functional Materials 2013, 23:3531-3538.

142. Hu Y, Gao J: Direct Imaging and Probing of the $\mathbf{p}-\mathbf{n}$ Junction in a Planar Polymer LightEmitting Electrochemical Cell. Journal of the American Chemical Society 2011, 133:2227-2231.

143. Shin J-H, Dzwilewski A, Iwasiewicz A, Xiao S, Fransson Å, Ankah GN, Edman L: Light emission at $\mathbf{5} \mathbf{V}$ from a polymer device with a millimeter-sized interelectrode gap. Applied Physics Letters 2006, 89:013509.

144. Bolink HJ, Coronado E, Costa RD, Orti E, Sessolo M, Graber S, Doyle K, Neuburger M, Housecroft CE, Constable EC: Long-Living Light-Emitting Electrochemical Cells - Control through Supramolecular Interactions. Advanced Materials 2008, 20:3910-+.

145. Bandiello E, Sessolo M, Bolink HJ: Lithium salt additives and the influence of their counterion on the performances of light-emitting electrochemical cells. Journal of Materials Chemistry C 2016, 4:10781-10785.

146. Lyons $\mathrm{CH}$, Abbas ED, Lee JK, Rubner MF: Solid-state light-emitting devices based on the trischelated ruthenium(II) complex. 1. Thin film blends with poly(ethylene oxide). Journal of the American Chemical Society 1998, 120:12100-12107.

147. Roldan-Carrnona C, Akatsuka T, Sessolo M, Watkins SE, Bolink HJ: Engineering Charge Injection Interfaces in Hybrid Light-Emitting Electrochemical Cells. Acs Applied Materials \& Interfaces 2014, 6:19520-19524.

148. Costa RD, Pertegas A, Orti E, Bolink HJ: Improving the Turn-On Time of Light-Emitting Electrochemical Cells without Sacrificing their Stability. Chemistry of Materials 2010, 22:1288-1290.

149. Tordera D, Meier S, Lenes M, Costa RD, Orti E, Sarfert W, Bolink HJ: Simple, Fast, Bright, and Stable Light Sources. Advanced Materials 2012, 24:897-+. 
150. Rudmann H, Rubner MF: Single layer light-emitting devices with high efficiency and long lifetime based on tris(2,2 ' bipyridyl) ruthenium(II) hexafluorophosphate. Journal of Applied Physics 2001, 90:4338-4345.

151. Bunzli AM, Constable EC, Housecroft CE, Prescimone A, Zampese JA, Longo G, Gil-Escrig L, Pertegas A, Orti E, Bolink HJ: Exceptionally long-lived light-emitting electrochemical cells: multiple intra-cation pi-stacking interactions in $\operatorname{Ir}(C N)(2)(N N)$ PF6 emitters. Chemical Science 2015, 6:2843-2852.

152. Costa RD, Orti E, Bolink HJ, Graber S, Housecroft CE, Constable EC: Efficient and LongLiving Light-Emitting Electrochemical Cells. Advanced Functional Materials 2010, 20:1511-1520.

153. Costa RD, Orti E, Bolink HJ, Graber S, Housecroft CE, Constable EC: Intramolecular piStacking in a Phenylpyrazole-Based Iridium Complex and Its Use in Light-Emitting Electrochemical Cells. Journal of the American Chemical Society 2010, 132:5978-+.

154. Costa RD, Orti E, Bolink HJ, Graber S, Housecroft CE, Neuburger M, Schaffner S, Constable EC: Two are not always better than one: ligand optimisation for long-living lightemitting electrochemical cells. Chemical Communications 2009:2029-2031.

155. Ertl CD, Momblona C, Pertegas A, Junquera-Hernandez JM, La-Placa MG, Prescimone A, Orti E, Housecroft CE, Constable EC, Bolink HJ: Highly Stable Red-Light-Emitting Electrochemical Cells. Journal of the American Chemical Society 2017, 139:3237-3248.

156. Pertegas A, Shavaleev NM, Tordera D, Orti E, Nazeeruddin MK, Bolink HJ: Host-guest blue light-emitting electrochemical cast. Journal of Materials Chemistry C 2014, 2:16051611.

157. Wang J, Tang S, Sandstrom A, Edman L: Combining an Ionic Transition Metal Complex with a Conjugated Polymer for Wide-Range Voltage-Controlled Light-Emission Color. Acs Applied Materials \& Interfaces 2015, 7:2784-2789.

158. Tracy C, Gao J: Polymer bulk homojunction photonic devices. Applied Physics Letters 2005, 87:143502.

159. Tracy C, Gao J: Polymer bulk homojunction light-emitting electrochemical cells. Journal of Applied Physics 2006, 100:104503.

160. Shih HC, Chiou BR, Su HC: Plasmonic enhancement in electroluminescence from lightemitting electrochemical cells incorporating gold nanourchins. Journal of Materials Chemistry C 2016, 4:5610-5616.

161. Lu JS, Kuo JC, Su HC: Solution-processable tandem solid-state light-emitting electrochemical cells. Organic Electronics 2013, 14:3379-3384.

162. Akatsuka T, Roldan-Carmona C, Orti E, Bolink HJ: Dynamically Doped White Light Emitting Tandem Devices. Advanced Materials 2014, 26:770-774.

163. Lee $C L$, Cheng CY, Su HC: Enhancing device efficiencies of solid-state near-infrared lightemitting electrochemical cells by employing a tandem device structure. Organic Electronics 2014, 15:711-720. 